\title{
Inflammatory Modulation of miR-155 Inhibits Doxorubicin-Induced Testicular Dysfunction Via Sirt1/Foxo1 Pathway: Insight to the Role of Acacetin and Bacillus Cereus Protease
}

\section{Hend Mohamed Anwar}

NODCAR: National Organization for Drug Control and Research

Sherin Ramadan Hamad

NODCAR: National Organization for Drug Control and Research

Gad Elsayed Mohamed Salem

NODCAR: National Organization for Drug Control and Research

Rania Hassan Mohamed Soliman

Zagazig University Faculty of Human Medicine

Eman Elbaz ( $\boldsymbol{D}$ eman.el-baz@pharm.cu.edu.eg )

CU Faculty of Pharmacy: Cairo University Faculty of Pharmacy https://orcid.org/0000-0003-3919-2612

\section{Research Article}

Keywords: Doxorubicin, miR-155, SIRT1, FOX01, acacetin, Bacillus Cereus protease.

Posted Date: January 31st, 2022

DOI: https://doi.org/10.21203/rs.3.rs-1282753/v1

License: (c) (1) This work is licensed under a Creative Commons Attribution 4.0 International License.

Read Full License 


\section{Abstract}

Purpose Doxorubicin (DOX), a chemotherapeutic agent, can disrupt testicular function leading to male infertility. The present study aimed to explore the possible protective effect of natural flavone, acacetin (ACA), and protease of Bacillus Cereus bacteria (B. Cereus) as well as the potential role of miR155/SIRT1/FOXO1 network in DOX-induced testicular toxicity.

Methods Twenty-eight male Wistar rats were randomly allocated into four groups and treated as follows: Control (1\% DMSO $1 \mathrm{~mL} / \mathrm{kg} /$ day; p.o), DOX (1 mg/kg, i.p) on every other day for 21 days with a cumulative dose equal to $10 \mathrm{mg} / \mathrm{kg}$ throughout the experimental period, pre-treated groups received ACA ( $5 \mathrm{mg} / \mathrm{kg} /$ day, p.o) or B. Cereus protease (36 mg/kg/day, p.o) for a week prior DOX administration.

Results DOX challenge reduced serum testosterone, and testicular $17 \beta$-hydroxysteroid dehydrogenase $(17 \beta-H S D)$. DOX exhibited a significant increase in testicular oxidative stress, inflammatory and apoptotic markers. Aberrant testicular miR-34c, a germ-specific miRNA, and miR-155 expressions were observed, along with decreased protein expression of sirtuin1 (SIRT1) dependent forkhead box 1 (FOXO1) acetylation inducing apoptosis. Besides, abnormal histopathological architecture and a marked reduction in the testicular expression of proliferating cell nuclear antigen (PCNA) were detected. ACA or protease administration significantly improves the histopathological and immunohistochemical pictures compared to DOX alone and renovated testicular functions. Nevertheless, treatment with protease was more effective than treatment with ACA in ameliorating DOX-induced testicular toxicity.

Conclusion This study reveals the prophylactic role of these two regimens on male fertility by exhibiting antioxidant, anti-inflammatory, and anti-apoptotic effects against DOX-elicited testicular toxicity, possibly via modulating miR-155/SIRT1/FOX01 network.

\section{Introduction}

Doxorubicin (DOX) is an anthracycline-derived antibiotic that is often used as a chemotherapy drug against solid and non-solid tumors (Wu et al. 2020). Doxorubicin's action is not limited to cancer cells; it can harm healthy cells as well, particularly those that have a rapid and continuous proliferative activity such as male sperm cells (Brilhante et al. 2012). It can impair spermatogenesis, trigger testicular toxicity, and eventually lead to male infertility (Howell and Shalet 2005).

Oxidative stress, lipid peroxidation, and apoptosis are considered the main mechanisms responsible for DOX-induced testicular toxicity (Suominen 2003; Kabel 2018). DOX appears to affect testicular integrity throughout both the prepubertal and post-pubertal phases of development (Ujah et al. 2021).

MicroRNAs (miRNAs) are non-coding RNAs of 19-25 nucleotides that have been reported to play important roles in a variety of biological processes (Bartel 2009). miRNAs are widely being addressed for their potential as diagnostic biomarkers and therapeutic targets in a variety of diseases (Li et al. 2016). Some miRNAs are elevated in oxidative stress and inflammatory responses and contribute to 
degenerative diseases (Marques-Rocha et al. 2015). miR-155 is one of the best-known miRNAs directly regulated by pro-inflammatory reactions (Onodera et al. 2017). It has been demonstrated that miR-155 overexpression has been linked to NF-kB transcriptional regulation, which is triggered by the inflammatory cytokine tumor necrosis factor-alpha (TNF- $囚$ ) (Li et al. 2016). Additionally, miR-155 directly regulates SIRT1, as the sirt1-regulated pathway can be inhibited by miR-155 overexpression (Wang et al. 2018). In the same context, miR-34 is highly expressed in vascular tissues (Yamakuchi 2012). miR-34c is a germ cell-specific microRNA that is abundantly expressed in the testis (Bouhallier et al. 2010). The activity of miR-34c is mediated by Bcl-2 since Bcl-2 is a direct target of miR-34c (Liu et al. 2012).

SIRT1 (Sirutin1) is a NAD-dependent deacetylase that can deacetylate a multiple of transcriptional factors, such as forkhead box O (FOXO), Nuclear factor-kappa B (NF-kB), and peroxisome proliferators activated receptor gamma coactivator-1a (PGC-1a) (Brunet et al. 2004; Yeung et al. 2004; Rodgers et al. 2005). It has been reported to play a crucial role in cellular proliferation and differentiation (Yamakuchi 2012). In vitro studies showed that SIRT1 could suppress the activity of Bcl-2-associated X protein (Bax), FOXO, and Rb (retinoblastoma) (Lim 2006; Ota et al. 2006). SIRT1 has been demonstrated to protect bcells from oxidative stress via a mechanism that involves the deacetylation of FOXO proteins (Kitamura et al. 2005).

Forkhead box transcription factors (Foxo) regulate several aspects of development, metabolism, and reproduction (Christian et al. 2011). There are three main Foxos in the Foxo family proteins: Foxo1, Foxo2, and Foxo4 (Zhao et al. 2011). The FOXO protein family is broadly responsible for cellular signal transduction, growth and development, apoptosis, and oxidative stress, among which FOXO1 and FOXO3 are the most prevalent (Ren et al. 2019). Foxo1 has been shown to play an important role in the male germline (Goertz et al. 2011). Foxo1 protein is expressed particularly in undifferentiated spermatogonia cells, which act as a stem cell population that drives spermatogenesis (Goertz et al. 2011). SIRT1 and FOXO interact in a complex way to protect against oxidative damage (Maiese et al. 2008). SIRT1 binds FOX01, inhibits its acetylation, and reduces its transcriptional activity (Yang et al. 2005). Cigarette smoke has been demonstrated to produce oxidative stress injury in lung cells by acting on the SIRT1/FOXO pathway (Hwang et al. 2014). Upon activation of the SIRT1/ FOXO pathway, the degree of FOXO deacetylation not only regulates oxidative stress but also controls cell apoptosis and the cell cycle, which is a complex and interactive process (Yang et al. 2005). Therefore, studies on the role of this pathway in the toxic injury of toxins should be more regarded.

Acacetin (5,7-dihydroxy-40-methoxy flavone), a natural flavone, occurs in a variety of plant pigments. It has anti-oxidative, anti-inflammatory, and anti-apoptotic effects (Wu et al. 2018). ACA is found to be effective in treating doxorubicin cardiomyopathy via enhancing AMPK/Nrf2 antioxidative signaling molecules (Wu et al. 2020). It protects the myocardium from ischemia/reperfusion and inhibits apoptosis of H9c2 cardiomyocytes through the PI3K-Akt pathway (Liu et al. 2019). Although ACA has its medicinal benefits, there is no information available regarding its effect on doxorubicin elicited testicular toxicity. 
Proteases are a new class of medicines with a lot of promise. In the human genome, more than $2 \%$ of genes code for proteases (Rodríguez et al. 2010). Proteases, for example, modulate growth factors, cytokines, chemokines, and cellular receptors, resulting in gene regulation and downstream intracellular signaling (Craik et al. 2011). Although proteases are synthesized by different plants, animals, and microorganisms, the latter are the most common in nature. Proteases are reportedly potential antiinflammatory agents. They have been shown to work in harmony with non-steroidal anti-inflammatory (NSAIDs) medications, either independently or synergistically. However, the use of NSAIDs has negative side effects. Therefore, using bioactives and enzymes with anti-inflammatory action will assist in reducing the use of NSAIDs (Viswanatha Swamy and Patil 2008). B. cereus is a type of gram-positive bacteria, producing an alkaline protease, commonly found in soil, and has previously exhibited high proteolytic activity. It has been reported that $B$. Cereus produces an enzyme that has fibrinolytic potential in vitro (Narasimhan et al. 2015).

Therefore, the current study was designed to evaluate the possible protective effect of ACA or $B$. Cereus protease against DOX-induced male infertility in rats and to investigate the possible role of the miR155/SIRT1/FOXO1 signaling pathway.

\section{Material And Methods}

\section{Animals}

Adult male Wistar albino rats, weighing 150-170 g, were obtained from the National Organization for Drug Control and Research (NODCAR), Cairo, Egypt. Rats were housed in stainless steel cages under controlled environmental conditions: temperature $\left(23 \pm 2^{\circ} \mathrm{C}\right)$, humidity $(60 \pm 10 \%)$, ventilation $10-20$ changes/ $\mathrm{h}$, and a $12 \mathrm{~h} / 12 \mathrm{~h}$ light and dark cycle at the animal house facility of the National Organization for Drug Control and Research, Cairo, Egypt. They were fed a standard chow diet and allowed water ad libitum. The investigation complies with the Guide for the Care and Use of Laboratory Animals and was approved by the Ethics Committee for Animal Experimentation at Faculty of Pharmacy, Cairo University (Permit Number: BC 3114).

\section{Drugs and chemicals}

Doxorubicin was obtained from Novartis Pharmaceutical Co. (El Amireya, Cairo, Egypt). Acacetin was purchased from Sigma-Aldrich (St. Louis, MO, United States), and diluted in dimethyl sulfoxide (DMSO) (Sigma-Aldrich, St. Louis, MO, United States). Protease of Bacillus cereus strain was isolated and purified as described below. All chemicals were of the highest purity and analytical grade.

\section{Microorganism and enzyme production}

The bacterial culture Bacillus cereus S6-3 was isolated from soil samples collected in Egypt's Sharkia governorate. Molecular identification and optimization of fermentation parameters for optimum enzyme production were previously reported (Abu El-Wafa et al. 2016). The medium used for the production of the 
enzyme by parent and mutant strains composed of $(\mathrm{g} / \mathrm{l})$ : skimmed milk, 6.0 , fructose, $10.0, \mathrm{~K}_{2} \mathrm{HPO}_{4}, 0.5$, yeast extract, $1.0, \mathrm{MgSO}_{4} \cdot 7 \mathrm{H}_{2} \mathrm{O}$,

1.0, $\mathrm{KCl}, 5.0, \mathrm{CaCl}_{2} \cdot 2 \mathrm{H}_{2} \mathrm{O}, 0.2, \mathrm{NaCl}, 5.0$, and the final pH was 6.0 (Abu El-Wafa et al. 2016). The selected mutant strain Bacillus cereus S6-3/UM90 for protease production was previously described (Abdel-Naby et al. 2020).

\section{Partial Purification of protease enzyme}

After centrifugation, the cultured media's clear supernatant was precipitated with acetone (KarbalaeiHeidari et al. 2009). Briefly, the cell-free supernatant and cooled acetone $\left(-20^{\circ} \mathrm{C}\right)$ were combined in a $1: 2$ ratio and centrifuged for 10 minutes at 10,000 rpm. The precipitate was collected and air-dried at room temperature. The dried pellet was re-suspended in a minimum volume of $10 \mathrm{mM}$ phosphate buffer $\mathrm{pH}$ 7.5. Partially purification of protease produced from mutant Bacillus cereus-S6-3/UM90 is shown in Table 1. The enzyme solution was first precipitated with acetone saturation, which increased the protease activity by 1.72 times with a $62 \%$ recovery, showing specific activity of $186 \mathrm{U} / \mathrm{mg}$ (Shaikh et al. 2018; Chandra et al. 2020).

Table 1

Summary of partial purification of protease obtained from Bacillus cereus-S6-3/UM90

\begin{tabular}{|lllllll|}
\hline $\begin{array}{l}\text { Purification } \\
\text { Steps }\end{array}$ & $\begin{array}{l}\text { Volume } \\
(\mathbf{m L})\end{array}$ & $\begin{array}{l}\text { Total } \\
\text { Activity } \\
(\mathbf{U})\end{array}$ & $\begin{array}{l}\text { Total } \\
\text { Protein } \\
(\mathbf{m g})\end{array}$ & $\begin{array}{l}\text { Specific Activity } \\
(\mathbf{U} / \mathrm{mg})\end{array}$ & $\begin{array}{l}\text { Yield or } \\
\text { Recovery } \\
(\%)\end{array}$ & $\begin{array}{l}\text { Fold } \\
\text { Purification }\end{array}$ \\
\hline $\begin{array}{l}\text { Acetone } \\
\text { treated }\end{array}$ & 100 & 42900 & 395 & 108 & 100 & 1 \\
\hline
\end{tabular}

\section{Estimation of enzymatic activity}

The proteolytic activity was measured according to Kembhavi et al. (Kembhavi et al. 1993), method with some minor modifications. Briefly, $5.0 \mathrm{ml}$ of $(1.0 \%, \mathrm{w} / \mathrm{v})$ casein (substrate) was prepared in $10 \mathrm{mM}$ carbonate-bicarbonate buffer-pH-10.5. $1.0 \mathrm{ml}$ of the supernatant solution was added to the substrate and incubated at $40^{\circ} \mathrm{C}$ for $10 \mathrm{~min}$. A blank test tube was incubated without the addition of enzyme solution. The enzymatic reaction was stopped by adding $5.0 \mathrm{ml}$ of $0.4 \mathrm{M}$ trichloroacetic acid solution. The reaction mixtures were allowed to stand for $25 \mathrm{~min}$ at room temperature. Then, the solutions were centrifuged at $5000 \mathrm{rpm}$ for $10 \mathrm{~min}$ to remove the precipitate. The absorbance of the clear supernatant was measured at $660 \mathrm{~nm}$. Tyrosine $(0-50 \mathrm{mg} / \mathrm{ml})$ calibration curve was used as a standard calibration curve. One protease activity unit was defined as the amount of enzyme required to liberate $1 \mathrm{mg}$ of tyrosine/ $\mathrm{ml} / \mathrm{min}$ under the standard experimental conditions.

\section{Experimental design}

In the current study, a total of 28 rats were randomly allocated into four groups (7 rats each), as follows: 
The first group received $1 \%$ dimethyl sulfoxide (DMSO) $(1 \mathrm{ml} / \mathrm{kg} /$ day) orally for 30 days and served as a control group.

The second group received DOX (1 mg/kg/i.p) in phosphate-buffered saline (PBS) every other day for 21 days (Yang et al. 2017) and served as a paradigm for reproductive toxicity. Animals in the group received cumulative doses of DOX equal to $10 \mathrm{mg} / \mathrm{kg}$ throughout the experimental period.

The third group received ACA ( $5 \mathrm{mg} / \mathrm{kg} /$ day p.o.) diluted in $1 \%$ DMSO for one week (Wei et al. 2020), then received DOX as in the second group concurrently with ACA ( $5 \mathrm{mg} / \mathrm{kg} /$ day p.o.) for 21 days.

The fourth group received bacterial protease ( $36 \mathrm{mg} / \mathrm{kg} /$ day, p.o.) for one week (Swamy and Patil 2008), then received DOX as in the second group concurrently with bacterial protease ( $36 \mathrm{mg} / \mathrm{kg} /$ day, p.o.) for 21 days.

Twenty-four hours after the end of the experiment, $2 \mathrm{ml}$ of blood were withdrawn from the retro-orbital plexus vein under light anesthesia (thiopental sodium $50 \mathrm{mg} / \mathrm{kg}$, ip), and sera were separated to determine serum testosterone levels. After that, animals were euthanized and both testes were immediately dissected out, washed, and dried. The right testis was fixed in $10 \%$ formalin solution for histopathological examination. A tissue portion of the left testis was homogenized in ice-cold buffered saline $(1: 9 \mathrm{w} / \mathrm{v})$ and aliquoted to scrutinize oxidative stress markers and 17 3 -HSD while, the remaining testicular tissue was kept at $-80^{\circ} \mathrm{C}$ for further biochemical analysis.

\section{Biochemical analysis}

\section{Testicular damage markers}

Serum testosterone level was measured by an ELISA kit supplied by Diametra (Perugia, Italy, Ref DK0015). Testicular 17Beta-Hydroxysteroid Dehydrogenase protein expression level was determined in tissue homogenate using an ELISA kit provided by MyBioSource, Inc. (San Diego, USA, Cat.No: MBS2104946) according to the manufacturer's instructions. The results are expressed as $\mathrm{pg} / \mathrm{ml}$ for serum testosterone and $\mathrm{ng} / \mathrm{g}$ tissue for $17 \beta-H S D$.

\section{Testicular redox state}

Tissue-reduced glutathione (GSH), and malondialdehyde (MDA) levels were determined as previously described (Sedlak and Lindsay 1968; Uchiyama and Mihara 1978). The results are expressed as $\mu \mathrm{mol} / \mathrm{g}$ tissue for GSH and nmol/g tissue for MDA. Meanwhile, nitric oxide (NO) level, SOD activity, and total antioxidant capacity (TAC) were measured by NO, SOD, and TAC kits, Biodiagnostics, Egypt, (cat. no. NO 2533 , SD 25 21, and TA 25 13, respectively). The results are expressed as $\mu \mathrm{mol} / \mathrm{L}$ for $\mathrm{NO}, \mathrm{U} / \mathrm{g}$ tissue for SOD, and $\mathrm{mM} / \mathrm{L}$ for TAC.

\section{qRT-PCR analysis of Nrf2, TLR4, NF- kB, Bax, and Bcl2 gene expressions}


To ensure genetic processing, samples were stored in RNA lysis solution at $-80^{\circ} \mathrm{C}$. The expression of Nrf2, TLR-4, NF- KB, Bax, and Bcl2 genes was assessed by real-time quantitative reverse transcription PCR (RTPCR). Following standard protocols, total RNA was converted into complementary DNA (CDNA) using ExcelRTTM Reverse Transcription Kit (SAMOBIO, Small Bio Smart tool, Cat. No. RP1300). The Real-Time PCR was conducted using a DTlite Real-Time PCR System (DTlite, DNA technology, LLC, Moscow, Russia) and BioEasy Sybr Green Master Mix (Bioer Technology, Cat No. BSB25L1) in a final volume of $25 \mathrm{~mL}$. Performed thermal cycling at $95^{\circ} \mathrm{C}$ for $15 \mathrm{~s}$, followed by 40 cycles at $95 \mathrm{C}$ for $15 \mathrm{~s}, 60 \mathrm{C}$ for $15 \mathrm{~s}$, and $72^{\circ} \mathrm{C}$ for $45 \mathrm{~s}$. The data were analyzed using ABI Prism software and quantified using PE Biosystems v1_7 Sequence Detection Software (Foster City, CA, USA). By using the comparative threshold cycle method, we calculated the relative expression of the genes studied. All values were normalized to the endogenous control gene GAPDH as an invariant control. Primer sequences for Nrf2, TLR4, NF-KB, Bax, and Bcl2 are shown in Table 2. 
Table 2

primers Sequence used in the experiment.

\begin{tabular}{|c|c|c|}
\hline Name of primer & Sequence & Accession No. \\
\hline \multirow[t]{4}{*}{ Nrf2 } & Forward & XM_032903520.1 \\
\hline & 5'CAAATCCCACСTTGAACACA 3' & \\
\hline & Reverse & \\
\hline & 5'CGACTGACTAATGGCAGCAG 3' & \\
\hline \multirow[t]{4}{*}{ TLR4 } & Forward & NM_021297.3 \\
\hline & 5'-CACTGTTCTTCTCCTGCCTGAC-3' & \\
\hline & Reverse & \\
\hline & 5'-TGG TTGAAGAAGGAATGTCATC-3' & \\
\hline \multirow[t]{4}{*}{ NF-KB } & Forward & NM_009045.5 \\
\hline & 5'-CCT CTGGCGAATGGCTTTAC-3' & \\
\hline & Reverse & \\
\hline & 5'-GCTATGGAT CTGCGGTCTGG-3' & \\
\hline \multirow[t]{4}{*}{ Bax } & Forward & XM_032915032.1 \\
\hline & 5'-GAACCATCATGGGCTGGACA-3' & \\
\hline & Reverse & \\
\hline & 5'-TGAGGTTTATTGGCGCCTCC-3' & \\
\hline \multirow[t]{4}{*}{$\mathrm{Bcl} 2$} & Forward & XM_034943915.1 \\
\hline & 5'-GAACTGGGGGAGGATTGTGG-3' & \\
\hline & Reverse & \\
\hline & 5'-ACTTCACTTGTGGCCCAGAT-3' & \\
\hline \multirow[t]{4}{*}{ GAPDH } & Forward & XM_034500817.1 \\
\hline & 5'-ACCACAGTCCATGCCATCAC-3' & \\
\hline & Reverse & \\
\hline & 5'-GTCCTCAGTGTAGCCCAGGA-3' & \\
\hline
\end{tabular}




\begin{tabular}{|lll|}
\hline Name of primer & Sequence & Accession No. \\
\hline miR-34c & Forward & XM_017596027.2 \\
& 5'-AGTTACTAGGCAGTGTAG-3' & \\
& Reverse & \\
& 5'-TCTTTTTACCTGGCCGTGT-3' & \\
miR-155 & Forward & NR_129131.2 \\
& 5'-TAATGCTAATCGTGATAGGGGTT-3' & \\
& Reverse & \\
& 5'-CACCGTACCCTGTTAATGCT -3' & \\
\hline RNU6B & Forward & XR_003233292.1 \\
& 5'-CTCGCTTCGGCAGCACA-3' & \\
& Reverse & \\
& 5'-AACGCTTCACGAATTTGCGT-3' & \\
\hline
\end{tabular}

Table 3

Correlations between different biomarkers in all studied groups.

\begin{tabular}{|c|c|c|c|c|c|c|}
\hline & MiR-34c & MiR-155 & SIRT1 & F0X01 & Testosterone & $17 \beta-H S D$ \\
\hline MiR-34c & 1 & $-0.706 * \star \star$ & 0.555 ** & -0.798 *** & 0.444 * & 0.499 * \\
\hline MiR-155 & $-0.706 * \star \star$ & 1 & $-0.794 * * \star$ & $0.89 * \star \star$ & $-0.771 * \star \star *$ & 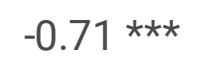 \\
\hline SIRT1 & 0.555 ** & $-0.794 * \star \star$ & 1 & -0.914 *** & 0.971 *** & $0.966 * * \star$ \\
\hline F0X01 & $-0.798 * \star *$ & $0.89 * * \star$ & $-0.917 * \star \star *$ & 1 & $-0.862 * * *$ & $-0.866 * * *$ \\
\hline
\end{tabular}

Values represent Pearson correlation coefficient. Correlation is significant at ${ }^{*} P<0.05,{ }^{\star} * P<0.01$, and $\star \star \star P<0.001$.

17ß-HSD: 17 beta-hydroxysteroid dehydrogenase; FOX01: Forkhead box protein 01; SIRT1: sirtuin1; miR: micro RNA

\section{Testicular miR-34c and miR-155}

TRIzoI ${ }^{\circledR}$ reagent (Invitrogen, Sigma-Aldrich, St. Louis, MO, USA) was used to extract total RNA from frozen samples while for evaluation of miRNA-34c and miRNA-155 using miRNeasy extraction Kit (QIAGEN, Cat. No. / ID: 217084). By standard protocols, total RNA was converted into complementary DNA (cDNA) using ExcelRTTM Reverse Transcription Kit (SAMOBIO, Small Bio Smart tool, Cat. No. RP1300). The RealTime PCR was conducted using a DTlite Real-Time PCR System (DTlite, DNA technology, LLC, Moscow, Russia) and BioEasy Sybr Green Master Mix (Bioer Technology, Cat No. BSB25L1) in a final volume of 25 $\mathrm{mL}$. Performed thermal cycling at $95^{\circ} \mathrm{C}$ for $15 \mathrm{~s}$, followed by 40 cycles at $95 \mathrm{C}$ for $15 \mathrm{~s}, 60 \mathrm{C}$ for $15 \mathrm{~s}$, and 
$72^{\circ} \mathrm{C}$ for $45 \mathrm{~s}$. Changes in the expression of each miRNA were normalized to the endogenous control gene RNU6B. Relative expression was calculated by $2-\Delta C t$ in each group. Primer sequences for the studied miR-34c and miR-155 are shown in Table 2.

\section{Testicular SIRT1 and F0X01}

Tissue Sirtuin 1 (SIRT1), and Forkhead Box Protein 01 (FOX01) were estimated using ELISA kits provided by MyBioSource, Inc. (San Diego, USA) (Cat.No: MBS060720, and MBS749342, respectively) according to the manufacturer's instructions, and the results are expressed as $\mathrm{ng} / \mathrm{g}$ tissue.

\section{Histopathological examination}

The right testis was fixed in $10 \%$ formalin for $24 \mathrm{~h}$. pieces of testis were dehydrated in increasing concentrations of alcohol and were cleaned in xylene before embedding in paraffin blocks. After that, the samples were embedded in paraffin wax. $5 \mu \mathrm{m}$ thick sections were deparaffinized with xylene, and stained with hematoxylin-eosin (H\&E) for analysis by light microscopy, and photomicrographs were captured at the power of $X 200$.

\section{Immunohistochemistry}

$4 \mu \mathrm{m}$ thick sections of the testis situated on a slide were put in a pressure cooker containing Tris-EDTA buffer with $0.05 \%$ tween 20 ( $\mathrm{pH}$ 9.0), for 3 min for antigen retrieval, followed by blocking of endogenous peroxidase with $3 \%$ hydrogen peroxide in phosphate-buffered saline for $5 \mathrm{~min}$, then washing with distilled water and Tris-buffered saline containing $0.05 \%$ tween 20 (TBST, pH 8.4). Thereafter, sections were incubated with polyclonal primary antibodies for TNF-a (1:120), cleaved caspase-3 (1:150), and PCNA (1:50) (Cloud-Clone Corp, USA) for $24 \mathrm{~h}$ at $4 \mathrm{\circ C}$. After washing with TBST, sections were incubated with Dako EnVision ${ }^{\text {TM }}+$ System/HRP labeled polymer containing goat anti-rabbit secondary antibody (Agilent Technologies, Inc. USA) for 30 min at room temperature. Visualization was performed using Dako 3,3'diaminobenzidine substrate (Agilent Technologies, Inc. USA) for $5 \mathrm{~min}$ at room temperature. Sections were counter-stained in hematoxylin for $5 \mathrm{~s}$, dehydrated, and viewed using a light microscope (Olympus BX41, UK). Additionally, quantitative measurement of percentage area of PCN, as well as TNF- $\triangle$ and caspase-3 immunostaining color intensity was quantified by analyzing the intensity of brown stain for photographs using J-Image software. (ImageJ, NIH-Bethesda, MD, USA).

\section{Statistical analysis}

The data are presented as mean \pm SD, with a one-way analysis of variance (ANOVA) followed by Tukey post-hoc test. Moreover, associations between different parameters were assessed using Pearson correlation analysis. GraphPad Prism software (version 8; GraphPad Software, Inc., San Diego, CA, USA) was used to perform the statistical analysis and present the data. The level of significance $P$-value $<0.05$ was fixed for all statistical tests.

\section{Results}


Effect of acacetin or B. Cereus protease on serum testosterone, and testicular 17 $\beta$-HSD in DOX-treated rats

As depicted in figures 1A \& 1B, DOX-induced a significant decrease in serum testosterone, and tissue 17 $\beta$ HSD by $93 \%$ and $68 \%$, respectively, compared to the control group at $p<0.05$. However, treatment with ACA or $B$. Cereus induced a significant increase in the aforementioned parameters compared to rats treated with DOX alone. Interestingly, the amelioration with a protease isolated from $B$. Cereus was better than with ACA.

Effect of ACA and B. Cereus protease on Oxidative stress biomarkers in DOX-induced testicular toxicity in rats

DOX significantly increased MDA level, and NO content in testis by 3- and 4-fold respectively, when compared to the control, whereas pre-treatment with ACA or B. Cereus protease considerably reduced the above-mentioned markers of oxidative stress (figure 2B). Similarly, Nrf2 gene expression, GSH, SOD, and TAC levels were significantly lowered in the testicular tissues of the DOX- only treated group by $70 \%, 50 \%$, $73 \%$, and $64 \%$, respectively, compared to the control (Figure 2A, 2B, 2C, \& 2D). However, pre-treatment with ACA or $B$. Cereus protease significantly improved the antioxidant parameters. Remarkably, the $B$. Cereus protease group showed a more ameliorative effect than the ACA treatment.

\section{Effect of ACA and B. Cereus protease on inflammatory biomarkers in DOX-induced testicular toxicity in rats}

DOX significantly upregulated the testicular gene expression of TLR-4, and NF-KB by 3- and 4.5-fold, respectively, as compared to the control group at $p<0.05$ (figure 3A \& 3B). Moreover, DOX showed positive immunostaining of TNF- $a$ (figure $3 \mathrm{C}$ ) as compared to the control group. Nevertheless, pretreatment with ACA or B. Cereus protease significantly halted the upregulation of these inflammatory biomarkers. However, the protease treated group showed a more pronounced effect than the ACA treated group.

Effect of ACA and B. Cereus protease on testicular miR-34c and miR-155 gene expression levels in DOXinduced testicular toxicity in rats

DOX treated rats induced a significant downregulation of miR-34c expression levels by $80 \%$ and a significant upregulation of miR-155 expression levels by 2.5 fold when compared to the control group. In contrast, pretreatment with either ACA or $B$. Cereus protease significantly reduced the changes in miRNAs expression levels (figure 4A).

Effect of ACA and B. Cereus protease on testicular SIRT1/FOX01 protein expression levels in DOXinduced testicular toxicity in rats

DOX treated group depicted a significant reduction in SIRT1 protein expression by $66 \%$ (figure 4B) and a subsequent significant increase in FOXO1 protein expression by 4 -fold (figure 4C) when compared to the 
control group. These impairments were restored in the bacterial protease treated group and ACA treated group.

\section{Effect of ACA and B. Cereus protease on apoptotic biomarkers in DOX-induced testicular toxicity in rats}

As demonstrated in figure 5A, a significant increase in Bax/Bcl2 ratio in DOX intoxicated group as compared to the control group. However, ACA treated group showed a significant reduction in $\mathrm{Bax} / \mathrm{Bcl} 2$ ratio. While bacterial protease treated group restored this ratio to the normal level as compared to DOX treated group. DOX group showed significant positive staining for caspase-3 as compared to the control group (figure $5 \mathrm{C}$ ). while bacterial protease treated group and ACA treated group showed a significant reduction in the staining intensity of caspase- 3 as compared to DOX treated rats.

Intriguingly, immunohistochemistry staining of testicular tissues from DOX treated rats showed that the most seminiferous tubules with negative PCNA expression, and another few seminiferous tubules with few PCNA immunoreactions in the nuclei of the spermatogenic cells and negative spermatocyte. On the other hand, the treatment with ACA or B. Cereus protease exhibited positive brown nuclei of spermatogonia and spermatocytes PCNA immunoreactions (figure 6A). This was presented by the ability of ACA or B. Cereus protease to normalize a reduction in the calculated area percentage of PCNA (figure 6B)

\section{Testicular histopathological examination}

Microscopically examination of testis sections stained with H\&E from the control group revealed normal testicular architecture with complete normal spermatogenic layers and well-developed sperm (Figure 7A). On the other hand, DOX provoked marked pathological alternations compared to control. Most areas revealed scattered seminiferous tubules with loosely normal architecture, hyaline degenerative changes accompanied by exfoliated spermatogenic cells in the lumen. In addition to the appearance of many scattered pyknotic nuclei in the basal cell layers of another seminiferous tubule. Marked widened interstitial areas with hemorrhage, thickened, hyalinized walls of blood vessels, and a marked reduction in interstitial Leydig cells were also noticed (Figure 7B1). Other areas showed scattered seminiferous tubules with severe degenerative changes, and a prominent reduction in spermatogenic layers and sperm (Figure 7B2) compared to the control group. However, pretreatment with ACA showed moderate improvement in the form of the normal appearance of spermatogenic layers and sperm in most of the seminiferous tubules. However, mild reduction in spermatogenic layers and a complete absence of sperm are occasionally seen in some seminiferous tubules. Mild widened interstitial spaces and moderated reductions in Leydig cells were also seen compared to the DOX group (Figure 7C). B. Cereus protease pretreatment group showed marked improvement as evidenced by no histological alterations in seminiferous tubules, complete spermatogenic layers and normal appearance of sperm and interstitial Leydig cells compared to the DOX treated group (Figure 7D).

\section{Correlation study}


We found several pronounced correlations between the considered parameters, as illustrated in Table 3 . miR-34c showed a positive correlation with SIRT1, serum testosterone, and 17 3 -HSD levels, while it was negatively correlated with miR-155, and FOX01. Alternatively, miR-155 exhibited a negative correlation with the aforementioned parameters and a positive correlation with FOX01. SIRT1, serum testosterone, and $17 \beta-H S D$ levels were positively correlated with each other and negatively correlated with FOXO1.

\section{Discussion}

Testicular toxicity is one of the most serious side effects of DOX which eventually leads to male infertility (Ujah et al. 2021). The current study reveals a protective effect of ACA and B. Cereus protease against DOX-induced male infertility in rats. Our findings also corroborate the involvement of miR-

155/SIRT1/FOXO1 signaling pathway in DOX-induced male infertility and indicate that modulation of this network is involved in the protective effect of ACA and B. Cereus protease.

In the current study, DOX revealed variable pathological changes compared to control. The results showed scattered seminiferous tubules with severe degenerative changes and a prominent reduction in spermatogenic layers and sperm count compared to the control group. In parallel, Dox elicited a marked decline in serum testosterone. This is in accordance with Rizk et al. (Rizk et al. 2014) who reported that DOX evoked a significant decrease in serum testosterone which will have an impact on spermatogenesis as well as on the structural morphology of the seminiferous tubules. In agreement with our findings, they also reported that DOX significantly dampened the activity of $17 \beta-H S D$ which is the principal enzyme in the synthesis of male sex hormone. Nevertheless, pre-administration with ACA or B.Cereus protease rescued the histological insults and the toxic effects of DOX on androgenic hormone synthesis, as proven with improved $\mathrm{H}$ \& E staining picture along with a marked increase in serum testosterone level and $17 \beta-$ HSD activity. Intriguingly, the amelioration with a protease isolated from B. Cereus was better than with ACA.

miR-34c is specifically expressed in germ cells. Bouhallier et al. (Bouhallier et al. 2010) observed the highest expression of miR-34c in the testis, with a lower one in the lungs and virtually no expression in other organs. Moreover, they suggested that miR-34c expression is directly related to germ cell numbers. Others showed that miR-34c is downregulated in the cryptorchidism model in mice (Huang et al. 2018). Moreover, miR-34c downregulation in prostate cancer was found to suppress tumor migration and invasion (Hagman et al. 2010). In accordance with the previous studies, our finding revealed a significant downregulation in miR-34c expression in DOX-intoxicated rats compared to the normal which was reversed by pre-administration of ACA or B. Cereus protease indicating their potential to guard against DOX-triggered male reproductive degeneration. Surprisingly, a protease isolated from B. Cereus was more effective than ACA.

$\mathrm{Nrf2}$ is a transcriptional factor that plays a fundamental role in the antioxidant defense mechanisms in several body tissues. It was proven to mitigate the toxicity of DOX, possibly through stimulation of antioxidant defense systems along with suppression of DOX-induced fibrotic and inflammatory 
responses (Kabel 2018). The role of Nrf2 in protection against DOX-induced testicular toxicity was confirmed by the data of the present study, where the addition of ACA or protease restored Nrf2 content and was associated with a significant increase in the activity of the antioxidant enzymes. Wu et al. (Wu et al. 2020) indicated that Nrf2 is important in mediating the protection of ACA against doxorubicin cardiotoxicity, which in turn boosts the antioxidant mechanisms, possibly through AMPK activation. In the same context, Cavello et al. (Cavello et al. 2021) reported the antioxidant potential of protease of bacteria Bacillus cytotoxicus.

Glutathione and SOD are nonenzymatic and enzymatic antioxidants that play a crucial role in ROS scavenging. Herein, as a result of DOX administration, the levels of these endogenous antioxidants decreased significantly, which could be due to increased production of DOX toxic metabolites or reduced production of antioxidant defense systems (Mohan et al. 2006), resulting in oxidative stress. ACA and B.Cereus proteinase were found to cause a significant elevation in GSH level and SOD activity, which agrees with the study by Wu et al. (Wu et al. 2020) who reported the antioxidant potential of ACA against doxorubicin cardiotoxicity using cultured rat cardiomyoblasts and by others who explored the antioxidant defense of proteases of Bacillus spp. (Rais et al. 2017)' (Cavello et al. 2021), indicating the antioxidant activity of ACA and B. Cereus protease in protection against doxorubicin testicular toxicity.

DOX-evoked testicular insult is exacerbated by oxidative stress. According to Uygur et al. (Uygur et al. 2014), DOX-induced DNA damage enhances the formation of reactive oxygen species (ROS) and represses the activities of antioxidant enzymes, causing a substantial deterioration of the testicular functions. The present study showed that the administration of DOX triggers oxidative stress and testicular lipid peroxidation. These findings are in harmony with previous studies that demonstrated severe pathologic alterations in the testicular tissue are linked to a high degree of lipid peroxidation, implying overproduction of reactive oxygen species (ROS) that may have a role in the testicular degeneration mechanism (Georgy and Maher 2017; Aksu et al. 2019). The increased malondialdehyde (MDA) levels in the DOX group can be related to the deteriorating changes in the testes, which might be linked to the male germ cell membrane that is abundant in polyunsaturated fatty acids (PUFA) making the testes susceptible to lipid peroxidation (Türedi et al. 2015). These effects were ameliorated upon treatment with ACA, which concurs with Wu et al. (Wu et al. 2021) who demonstrated a significant reduction in MDA by different concentrations of acacetin as well as Shiravi et al. (Shiravi et al. 2020) who reported that ACA produced inhibition of renal MDA and elevation of TAC in ischemic reperfusion rat kidney. Additionally, B. Cereus protease was able to counteract increase the production of ROS and lipid peroxidation, which is in the same line as Manivasagan et al. (Manivasagan et al. 2013) who documented the antioxidant effects of protease from Streptomyces spp.

Nitric oxide is a reactive nitrogen species that contribute significantly to nitrosative stress. The present study found that a significant increase in testicular NO levels in the DOX-treated group contributed to increased nitrosative stress. This might be due to reduced SOD activity, which increased the availability of superoxide anion radicals, which then reacted with available NO to produce peroxynitrite, a cytotoxic 
agent and powerful radical (Olusoji et al. 2017). On the other hand, pre-administration of ACA or the protease resulted in reduced NO overproduction and hence reduced nitrosative strain.

oxidative stress is frequently associated with inflammation, as ROS can trigger pro-inflammatory transcription factors (Nna et al. 2019). This study showed upregulation of the pro-inflammatory transcription factors TLR4, NF-KB, and TNF-a which coincides with previous studies demonstrating that DOX upregulated NF-KB and enhanced pro-inflammatory markers in the heart (Nna et al. 2019) and testis (Olusoji et al. 2017). Additionally, our findings are in line with others (Craik et al. 2011; Shokri et al. 2020) who demonstrated the potential of the proteases and ACA to reduce and alleviate inflammation, suggesting the anti-inflammatory potential of both regimens.

SIRT1, a deacetylase for many transcription factors, including FOX01, has been shown to regulate key cellular processes, including proliferation, differentiation, and apoptosis. miR-155 was shown to be a direct target of SIRT1 as miR-155 downregulated SIRT1 mainly through SIRT1 3' UTR binding. The current

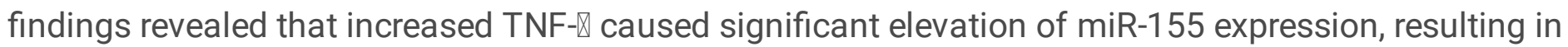
SIRT1 protein suppression in the DOX-treated group. These findings are in harmony with Guo et al (Guo et

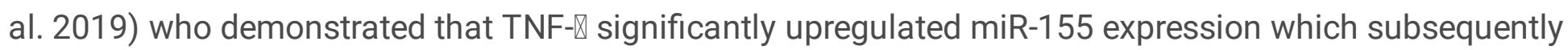
reduced SIRT1 expression. However, administration of ACA or B.Cereus protease dampened the expression of miR-155 that may be contributed to reduced TNF-囚-induced SIRT1 suppression, suggesting the anti-inflammatory effect of ACA and B.Cereus protease against DOX-induced testicular insults in rats via suppression of miR-155 and promotion of SIRT1 expressions.

The FOXO protein family is primarily controlled by post-translational modifications, including phosphorylation, and acetylation. Subcellular localization and protein expression levels, as well as DNA binding and transcriptional activity, might all be regulated by these post-translational changes (Oh et al. 2020). FOXO1 is expressed in many cell types and tissues throughout development, including endothelial cells, smooth muscle cells, neural crest cells, and male germ cells (Oh et al. 2020). Tothova \& Gilliland (Tothova and Gilliland 2007) have identified FOXO1 as a requirement in spermatogenesis, ranging from long-term spermatogonial stem cell (SSC) self-renewal through spermatogenesis and meiosis, as well as germ cell survival. Changes in FOXO1 expression would lead to spermatogenetic failure (Salih and Brunet 2008; Goertz et al. 2011). However, there have not been enough studies about the functional role of FOX01 in DOX-induced testicular dysfunction. FOX01 was a potential target for SIRT1 since SIRT1 could directly inhibit the expression of FOXO1via its deacetylation (Gu et al. 2016; Zhang et al. 2017). Our findings revealed that DOX-induced SIRT1 downregulation via miR-155 upregulation, leading to acetylation and activation of FOXO1 triggered apoptosis, suggesting the regulatory role of FOXO1 in doxorubicin-induced testicular apoptosis. Our results could be compatible with previous studies, considering oxidative stress as one of the key mechanisms of doxorubicin-induced testicular toxicity (Rizk et al. 2014; Gurel et al. 2019; Owumi et al. 2020). However, the data showed downregulation of FOXO1 expression after administration of ACA or B. protease, which could be thanks to SIRT1 suppressing FOXO1 provoked cell apoptosis through its deacetylation. The current data provide experimental evidence that miR-155 promotes testicular apoptosis through modulation of SIRT1- 
dependant FOXO1 acetylation in DOX-induced testicular toxicity. Additionally, our findings show a new therapeutic approach of ACA and B.Cereus proteinase that rescues DOX-induced testicular degeneration via modulation of miR-155/SIRT1/FOXO1 network.

Expression of PCNA in spermatogonia and early phase primary spermatocytes at all stages of the seminiferous tubules are the characterization of testicular tissues. The decrease in these cells produced by various chemicals is because spermatogonia differentiation is a particularly vulnerable stage in the spermatogenic process (Kang et al. 1997). In our study, PCNA-positive cells were strongly detected in spermatogonia of control rats. However, the number of PCNA-positive cells was considerably lower in the DOX-treated group. The decrease in PCNA in testicular germ cells implies a reduction in proliferative activity and spermatogenesis. This observation is in harmony with other studies (Magelssen et al. 2006; Salmand et al. 2008). DOX treatment is known to induce cell cycle arrest and death in replicating somatic cells (Salmand et al. 2008). In this study, the PCNA was reduced in the DOX group. On the contrary, there was an increase in testicular expression of PCNA in the ACA or B. Cereus group compared with the DOXtreated group.

The $\mathrm{Bcl}-2$ family is a key regulator of the apoptotic pathway, involving the pro-apoptotic $\mathrm{Bax}$ and $\mathrm{BH} 3$ subfamily (also known as BH3-only protein) and anti-apoptotic Bcl-2 subfamily (Senft et al. 2015). Bim (Bcl-2 interacting mediator of cell death), one of the $\mathrm{BH} 3$-only proteins, has been demonstrated as one of FOXOs downstream target genes that can interact with Bax/Bcl-2 thus activating the Bax-induced mitochondrial pathway (Marani et al. 2002; Mubarak et al. 2009). Yao et al. (Yao et al. 2018) showed that Bim expression was significantly increased in $\mathrm{H} 2 \mathrm{O} 2$ treated cells and reduced in cells with SIRT1 overexpression, indicating that SIRT1 inhibits Bim expression by mediating FOXOs. Together with these results, we found that an elevation of the testis apoptotic BAX/Bcl2 ratio in DOX-intoxicated rats was ameliorated upon pretreatment with ACA or protease, suggesting the role of both prophylactic regimes on modulating FOXO inducing apoptosis. In the same context, higher caspase-3 expressions were detected in DOX testicular, which agrees with the study by Tacar \& Dass (Tacar and Dass 2013). However, ACA or the protease pretreated group showed lower expressions of testicular caspase 3 . This reveals that both pretreatment regimes can alleviate the apoptotic signaling cascade pathway induced by DOX. These results reveal that DOX impaired rat testicular architecture and spermatogenesis via inducing cell apoptosis, while ACA or B. Cereus pre-treatment effectively protected against testicular apoptosis indicating their role as a novel therapeutic window for the management of reproductive toxicity associated with chemotherapeutic drugs such as DOX.

\section{Conclusion}

The current study is the first to introduce ACA or B. Cereus protease as a potential therapeutic agent prior to DOX chemotherapy that could offer protective influence against the detrimental effect of DOX on the male reproductive system through modulation of miR-155/SIRT1/FOX01 molecules. Thereby, improving the quality of life and men's self-image. 


\section{Declarations}

Acknowledgments Not applicable.

\section{Ethical approval}

All procedures including animals were approved and performed according to the guidelines of the Ethics Committee for Animal Experimentation at Faculty of Pharmacy, Cairo University (Permit Number: BC 3114).

\section{Author contributions}

HMA, EME: conceived and designed the experiments. HMA, SRH, GEMS, EME: conducted the experiments. EME, SRH: analyzed the data. HMA, SRH, GEMS, EME: wrote the manuscript. HMA, SRH, GEMS, RHMS, EME: provided reagents and analytical tools. The authors declare that all data were generated in-house and that no paper mill was used.

\section{Funding}

This research did not receive any specific grant from funding agencies in the public, commercial or not-for-profit sectors.

Competing Interests The authors declare no conflicts of interest.

\section{Availability of the data and materials}

The data and materials are available.

\section{References}

1. Abdel-Naby MA, El-Wafa WMA, Salem GEM (2020) Molecular characterization, catalytic, kinetic and thermodynamic properties of protease produced by a mutant of Bacillus cereus-S6-3. International Journal of Biological Macromolecules 160:695-702. https://doi.org/10.1016/j.jibiomac.2020.05.241

2. Abu El-Wafa WM, Salim GEM, Khedr FG, Abdel-Naby MA (2016) Optimization of medium compositions and cultural conditions for increasing of extracellular protease production from Bacillus cereus- S6-3. Der Pharmacia Lettre 8:400-412

3. Aksu EH, Kandemir FM, Yıldırım S, et al (2019) Palliative effect of curcumin on doxorubicin-induced testicular damage in male rats. Journal of Biochemical and Molecular Toxicology 33:1-8. https://doi.org/10.1002/jbt.22384

4. Bartel DP (2009) MicroRNAs: Target Recognition and Regulatory Functions. Cell 136:215-233. https://doi.org/10.1016/j.cell.2009.01.002 
5. Bouhallier F, Allioli N, Lavial F, et al (2010) Role of miR-34c microRNA in the late steps of spermatogenesis. Rna 16:720-731. https://doi.org/10.1261/rna.1963810

6. Brilhante O, Okada FK, Sasso-Cerri E, et al (2012) Late morfofunctional alterations of the Sertoli cell caused by doxorubicin administered to prepubertal rats. Reproductive Biology and Endocrinology 2012 10:1 10:1-16. https://doi.org/10.1186/1477-7827-10-79

7. Brunet A, Sweeney LB, Sturgill JF, et al (2004) Stress-dependent regulation of FOXO transcription factors by the SIRT1 deacetylase. Science (New York, NY) 303:2011-2015. https://doi.org/10.1126/SCIENCE.1094637

8. Cavello I, Bezus B, Cavalitto S (2021) The keratinolytic bacteria Bacillus cytotoxicus as a source of novel proteases and feather protein hydrolysates with antioxidant activities. Journal of Genetic Engineering and Biotechnology 19:1-12. https://doi.org/10.1186/s43141-021-00207-1

9. Chandra SJ, Shanker AS, Pindi PK (2020) Isolation and characterization of novel and efficient protease producing bacteria from drinking water resources. Water Supply 20:157-164. https://doi.org/10.2166/WS.2019.150

10. Christian M, W.-F. Lam E, S.C. Wilson M, J. Brosens J (2011) FOXO Transcription Factors and their Role in Disorders of the Female Reproductive Tract. Current Drug Targets 12:1291-1302. https://doi.org/10.2174/138945011796150253

11. Craik CS, Page MJ, Madison EL (2011) Proteases as therapeutics HHS Public Access. 435:1-16. https://doi.org/10.1042/BJ20100965.Proteases

12. Georgy GS, Maher OW (2017) Ellagic acid and rosmarinic acid attenuate doxorubicin-induced testicular injury in rats. Journal of Biochemical and Molecular Toxicology 31:1-6. https://doi.org/10.1002/jbt.21937

13. Goertz MJ, Wu Z, Gallardo TD, et al (2011) Foxo1 is required in mouse spermatogonial stem cells for their maintenance and the initiation of spermatogenesis. Journal of Clinical Investigation 121:34563466. https://doi.org/10.1172/JCl57984

14. Gu X, Han D, Chen W, et al (2016) SIRT1-mediated FoxOs pathways protect against apoptosis by promoting autophagy in osteoblast-like MC3T3-E1 cells exposed to sodium fluoride. Oncotarget 7:65218-65230. https://doi.org/10.18632/oncotarget.11573

15. Guo Q, Zhang H, Zhang B, et al (2019) Tumor Necrosis Factor-alpha (TNF-a) Enhances miR-155Mediated Endothelial Senescence by Targeting Sirtuin1 (SIRT1). Medical Science Monitor 25:88208835. https://doi.org/10.12659/MSM.919721

16. Gurel C, Kuscu GC, Buhur A, et al (2019) Fluvastatin attenuates doxorubicin-induced testicular toxicity in rats by reducing oxidative stress and regulating the blood-testis barrier via mTOR signaling pathway. Human and Experimental Toxicology 38:1329-1343. https://doi.org/10.1177/0960327119862006

17. Hagman Z, Larne O, Edsjö A, et al (2010) MiR-34c is downregulated in prostate cancer and exerts tumor suppressive functions. International Journal of Cancer 127:2768-2776. https://doi.org/10.1002/ijc.25269 
18. Howell SJ, Shalet SM (2005) Spermatogenesis After Cancer Treatment: Damage and Recovery. JNCI Monographs 2005:12-17. https://doi.org/10.1093/JNCIMONOGRAPHS/LGI003

19. Huang Z, Tang D, Gao J, et al (2018) miR-34c disrupts spermatogonial stem cell homeostasis in cryptorchid testes by targeting Nanos2. Reproductive Biology and Endocrinology 16:97. https://doi.org/10.1186/s12958-018-0417-z

20. Hwang J, Sundar IK, Yao H, et al (2014) Circadian clock function is disrupted by environmental tobacco/cigarette smoke, leading to lung inflammation and injury via a SIRT1-BMAL1 pathway. The FASEB Journal 28:176-194. https://doi.org/10.1096/fj.13-232629

21. Kabel AM (2018) Zinc/alogliptin combination attenuates testicular toxicity induced by doxorubicin in rats: Role of oxidative stress, apoptosis and TGF- $\beta 1 / N F-K B$ signaling. Biomedicine \& Pharmacotherapy 97:439-449. https://doi.org/10.1016/j.biopha.2017.10.144

22. Kang MJ, Kim MK, Terhune A, et al (1997) Cytoplasmic localization of cyclin D3 in seminiferous tubules during testicular development. Experimental cell research 234:27-36. https://doi.org/10.1006/EXCR.1997.3590

23. Karbalaei-Heidari HR, Amoozegar MA, Hajighasemi M, et al (2009) Production, optimization and purification of a novel extracellular protease from the moderately halophilic bacterium Halobacillus karajensis. Journal of Industrial Microbiology \& Biotechnology 36:21-27. https://doi.org/10.1007/s10295-008-0466-y

24. Kembhavi AA, Kulkarni A, Pant A (1993) Salt-tolerant and thermostable alkaline protease fromBacillus subtilis NCIM No. 64. Applied Biochemistry and Biotechnology 38:83-92. https://doi.org/10.1007/BF02916414

25. Kitamura YI, Kitamura T, Kruse J-P, et al (2005) Fox01 protects against pancreatic $\beta$ cell failure through NeuroD and MafA induction. Cell Metabolism 2:153-163. https://doi.org/10.1016/j.cmet.2005.08.004

26. Li X, Kong D, Chen H, et al (2016) MiR-155 acts as an anti-inflammatory factor in atherosclerosisAssociated foam cell formation by repressing calcium-regulated heat stable protein 1 . Scientific Reports 6:1-11. https://doi.org/10.1038/srep21789

27. Lim C-S (2006) SIRT1: Tumor promoter or tumor suppressor? Medical Hypotheses 67:341-344. https://doi.org/10.1016/j.mehy.2006.01.050

28. Liu C, Shen J, Yang W, Chen W (2019) Acacetin protective myocardial ischemia / reperfusion injury and inhibits apoptosis of H9c2 cardiomyocytes via the PI3K-Akt pathway. 12:9944-9952

29. Liu WM, Pang RTK, Chiu PCN, et al (2012) Sperm-borne microRNA-34c is required for the first cleavage division in mouse. Proceedings of the National Academy of Sciences of the United States of America 109:490-494. https://doi.org/10.1073/pnas.1110368109

30. Magelssen H, Brydøy M, Fosså SD (2006) The effects of cancer and cancer treatments on male reproductive function. Nature clinical practice Urology 3:312-322. https://doi.org/10.1038/NCPUR00508 
31. Maiese K, Chong ZZ, Shang YC (2008) OutFOXOing disease and disability: the therapeutic potential of targeting FoxO proteins. Trends in Molecular Medicine 14:219-227.

https://doi.org/10.1016/j.molmed.2008.03.002

32. Manivasagan P, Venkatesan J, Sivakumar K, Kim S-K (2013) Production, Characterization and Antioxidant Potential of Protease from Streptomyces sp. MAB18 Using Poultry Wastes. BioMed Research International 2013:1-12. https://doi.org/10.1155/2013/496586

33. Marani M, Tenev T, Hancock D, et al (2002) Identification of Novel Isoforms of the BH3 Domain Protein Bim Which Directly Activate Bax To Trigger Apoptosis. Molecular and Cellular Biology 22:3577-3589. https://doi.org/10.1128/MCB.22.11.3577-3589.2002

34. Marques-Rocha JL, Samblas M, Milagro Fl, et al (2015) Noncoding RNAs, cytokines, and inflammation-related diseases. The FASEB Journal 29:3595-3611. https://doi.org/10.1096/fj.14260323

35. Mohan IK, Kumar KV, Naidu MUR, et al (2006) Protective effect of CardiPro against doxorubicininduced cardiotoxicity in mice. Phytomedicine 13:222-229.

https://doi.org/10.1016/j.phymed.2004.09.003

36. Mubarak B, Soriano FX, Hardingham GE (2009) Synaptic NMDAR activity suppresses FOXO1 expression via a cis-acting FOXO binding site: FOXO1 is a FOXO target gene. Channels 3:233-239. https://doi.org/10.4161/chan.3.4.9381

37. Narasimhan MK, Chandrasekaran M, Rajesh M (2015) Fibrinolytic enzyme production by newly isolated Bacillus cereus SRM-001 with enhanced in-vitro blood clot lysis potential. The Journal of General and Applied Microbiology 61:157-164. https://doi.org/10.2323/jgam.61.157

38. Nna VU, Abu Bakar AB, Ahmad A, et al (2019) Oxidative Stress, NF-kB-Mediated Inflammation and Apoptosis in the Testes of Streptozotocin-Induced Diabetic Rats: Combined Protective Effects of Malaysian Propolis and Metformin. Antioxidants 8:465. https://doi.org/10.3390/antiox8100465

39. Oh J, Lee BS, Lim G, et al (2020) Atorvastatin protects cardiomyocyte from doxorubicin toxicity by modulating survivin expression through FOXO1 inhibition. Journal of Molecular and Cellular Cardiology 138:244-255. https://doi.org/10.1016/j.yjmcc.2019.12.007

40. Olusoji MJ, Oyeyemi OM, Asenuga ER, et al (2017) Protective effect of Gallic acid on doxorubicininduced testicular and epididymal toxicity. Andrologia 49:e12635. https://doi.org/10.1111/and.12635

41. Onodera $Y$, Teramura $T$, Takehara $T$, et al (2017) miR-155 induces $<s c p>R O S</ s c p>$ generation through downregulation of antioxidation-related genes in mesenchymal stem cells. Aging Cell 16:1369-1380. https://doi.org/10.1111/acel.12680

42. Ota $H$, Tokunaga $E$, Chang $K$, et al (2006) Sirt1 inhibitor, Sirtinol, induces senescence-like growth arrest with attenuated Ras-MAPK signaling in human cancer cells. Oncogene 25:176-185. https://doi.org/10.1038/sj.onc.1209049

43. Owumi SE, ljadele AO, Arunsi UO, Odunola OA (2020) Luteolin abates reproductive toxicity mediated by the oxido-inflammatory response in Doxorubicin-treated rats. Toxicology Research and 
Application 4:239784732097204. https://doi.org/10.1177/2397847320972040

44. Rais A, Jabeen Z, Shair F, et al (2017) Bacillus spp., a bio-control agent enhances the activity of antioxidant defense enzymes in rice against Pyricularia oryzae. PLOS ONE 12:e0187412. https://doi.org/10.1371/journal.pone.0187412

45. Ren Z, He H, Zuo Z, et al (2019) The role of different SIRT1-mediated signaling pathways in toxic injury. Cellular and Molecular Biology Letters 24:1-10. https://doi.org/10.1186/s11658-019-0158-9

46. Rizk SM, Zaki HF, Mina MAM (2014) Propolis attenuates doxorubicin-induced testicular toxicity in rats. Food and Chemical Toxicology 67:176-186. https://doi.org/10.1016/j.fct.2014.02.031

47. Rodgers JT, Lerin C, Haas W, et al (2005) Nutrient control of glucose homeostasis through a complex of PGC-1a and SIRT1. Nature 434:113-118. https://doi.org/10.1038/nature03354

48. Rodríguez D, Morrison CJ, Overall CM (2010) Matrix metalloproteinases: What do they not do? New substrates and biological roles identified by murine models and proteomics. Biochimica et Biophysica Acta (BBA) - Molecular Cell Research 1803:39-54. https://doi.org/10.1016/j.bbamcr.2009.09.015

49. Salih DA, Brunet A (2008) FoxO transcription factors in the maintenance of cellular homeostasis during aging. Current Opinion in Cell Biology 20:126-136. https://doi.org/10.1016/j.ceb.2008.02.005

50. Salmand PA, Jungas T, Fernandez M, et al (2008) Mouse heat-shock factor 1 (HSF1) is involved in testicular response to genotoxic stress induced by doxorubicin. Biology of reproduction 79:10921101. https://doi.org/10.1095/BIOLREPROD.108.070334

51. Sedlak J, Lindsay RH (1968) Estimation of total, protein-bound, and nonprotein sulfhydryl groups in tissue with Ellman's reagent. Analytical Biochemistry 25:192-205. https://doi.org/10.1016/00032697(68)90092-4

52. Senft D, Weber A, Saathoff F, et al (2015) In non-transformed cells Bak activates upon loss of antiapoptotic Bcl-XL and $\mathrm{Mcl}-1$ but in the absence of active BH3-only proteins. Cell Death \& Disease 6:e1996-e1996. https://doi.org/10.1038/cddis.2015.341

53. Shaikh IK, Dixit PP, Shaikh TM (2018) Purification and characterization of alkaline soda-bleach stable protease from Bacillus sp. APP-07 isolated from Laundromat soil. Journal of Genetic Engineering and Biotechnology 16:273-279. https://doi.org/10.1016/j.jgeb.2018.07.003

54. Shiravi A, Jalili C, Vaezi G, et al (2020) Acacetin Attenuates Renal Damage-Induced by IschemiaReperfusion with Declining Apoptosis and Oxidative Stress in Mice. International Journal of Preventive Medicine 11:. https://doi.org/10.4103/IJPVM.IJPVM_512_18

55. Shokri V, Jalili C, Raissi F, et al (2020) Evaluating the effects of acacetin versus a low dose of cisplatin drug on male reproductive system and kidney in mice: With emphasis on inflammation process. Andrologia 52:. https://doi.org/10.1111/and.13444

56. Suominen J (2003) The effects of mono-2-ethylhexyl phathalate, adriamycin and N-ethyl-Nnitrosourea on stage-specific apoptosis and DNA synthesis in the mouse spermatogenesis. Toxicology Letters 143:163-173. https://doi.org/10.1016/S0378-4274(03)00170-X 
57. Swamy AH. V, Patil P (2008) Effect of some clinically used proteolytic enzymes on inflammation in rats. Indian Journal of Pharmaceutical Sciences 70:114. https://doi.org/10.4103/0250-474X.4034

58. Tacar O, Dass CR (2013) Doxorubicin-induced death in tumour cells and cardiomyocytes: is autophagy the key to improving future clinical outcomes? Journal of Pharmacy and Pharmacology 65:1577-1589. https://doi.org/10.1111/jphp.12144

59. Tothova Z, Gilliland DG (2007) FoxO Transcription Factors and Stem Cell Homeostasis: Insights from the Hematopoietic System. Cell Stem Cell 1:140-152. https://doi.org/10.1016/j.stem.2007.07.017

60. Türedi S, Yuluğ E, Alver A, et al (2015) Effects of resveratrol on doxorubicin induced testicular damage in rats. Experimental and Toxicologic Pathology 67:229-235.

https://doi.org/10.1016/j.etp.2014.12.002

61. Uchiyama M, Mihara M (1978) Determination of malonaldehyde precursor in tissues by thiobarbituric acid test. Analytical Biochemistry 86:271-278. https://doi.org/10.1016/00032697(78)90342-1

62. Ujah GA, Nna VU, Suleiman JB, et al (2021) Tert-butylhydroquinone attenuates doxorubicin-induced dysregulation of testicular cytoprotective and steroidogenic genes, and improves spermatogenesis in rats. Scientific Reports 11:5522. https://doi.org/10.1038/s41598-021-85026-7

63. Uygur R, Aktas C, Tulubas F, et al (2014) Protective effects of fish omega-3 fatty acids on doxorubicin-induced testicular apoptosis and oxidative damage in rats. Andrologia 46:917-926. https://doi.org/10.1111/and.12173

64. Viswanatha Swamy AH., Patil P (2008) Effect of some clinically used proteolytic enzymes on inflammation in rats. Indian Journal of Pharmaceutical Sciences 70:114. https://doi.org/10.4103/0250-474X.40347

65. Wang Y, Zheng Z ji, Jia Y jie, et al (2018) Role of p53/miR-155-5p/sirt1 loop in renal tubular injury of diabetic kidney disease. Journal of Translational Medicine 16:1-9. https://doi.org/10.1186/s12967018-1486-7

66. Wei Y, Yuan P, Zhang Q, et al (2020) Acacetin improves endothelial dysfunction and aortic fibrosis in insulin-resistant SHR rats by estrogen receptors. Molecular Biology Reports 47:6899-6918. https://doi.org/10.1007/s11033-020-05746-3

67. Wu W-Y, Li Y-D, Cui Y-K, et al (2018) The Natural Flavone Acacetin Confers Cardiomyocyte Protection Against Hypoxia/Reoxygenation Injury via AMPK-Mediated Activation of Nrf2 Signaling Pathway. Frontiers in Pharmacology 9:1-16. https://doi.org/10.3389/fphar.2018.00497

68. Wu WY, Cui YK, Hong YX, et al (2020) Doxorubicin cardiomyopathy is ameliorated by acacetin via Sirt1-mediated activation of AMPK/Nrf2 signal molecules. Journal of Cellular and Molecular Medicine 24:12141-12153. https://doi.org/10.1111/jcmm.15859

69. Wu Y, Song F, Li Y, et al (2021) Acacetin exerts antioxidant potential against atherosclerosis through Nrf2 pathway in apoE -/- Mice. Journal of Cellular and Molecular Medicine 25:521-534. https://doi.org/10.1111/jcmm.16106 
70. Yamakuchi M (2012) MicroRNA regulation of SIRT1. Frontiers in Physiology 3 MAR:1-8. https://doi.org/10.3389/fphys.2012.00068

71. Yang CC, Chen YT, Chen $\mathrm{CH}$, et al (2017) Assessment of doxorubicin-induced mouse testicular damage by the novel second-harmonic generation microscopy. American Journal of Translational Research 9:5275-5288

72. Yang Y, Hou H, Haller EM, et al (2005) Suppression of FOXO1 activity by FHL2 through SIRT1mediated deacetylation. EMBO Journal 24:1021-1032. https://doi.org/10.1038/sj.emboj.7600570

73. Yao H, Yao Z, Zhang S, et al (2018) Upregulation of SIRT1 inhibits H2O2-induced osteoblast apoptosis eia Fox01/ $\beta$-catenin pathway. Molecular Medicine Reports 17:6681-6690. https://doi.org/10.3892/mmr.2018.8657

74. Yeung F, Hoberg JE, Ramsey CS, et al (2004) Modulation of NF-kB-dependent transcription and cell survival by the SIRT1 deacetylase. The EMBO Journal 23:2369-2380. https://doi.org/10.1038/sj.emboj.7600244

75. Zhang M, Zhang Q, Hu Y, et al (2017) miR-181a increases FoxO1 acetylation and promotes granulosa cell apoptosis via SIRT1 downregulation. Cell Death \& Disease 8:e3088-e3088. https://doi.org/10.1038/cddis.2017.467

76. Zhao Y, Wang Y, Zhu W-G (2011) Applications of post-translational modifications of FoxO family proteins in biological functions. Journal of Molecular Cell Biology 3:276-282. https://doi.org/10.1093/jmcb/mjr013

\section{Figures}


(A)

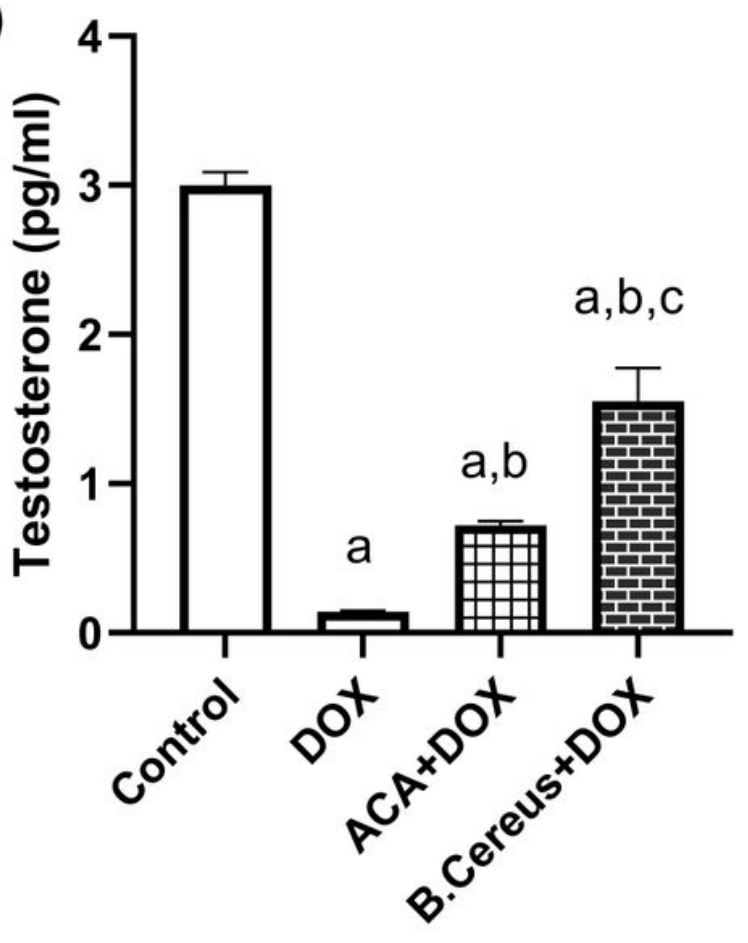

(B)

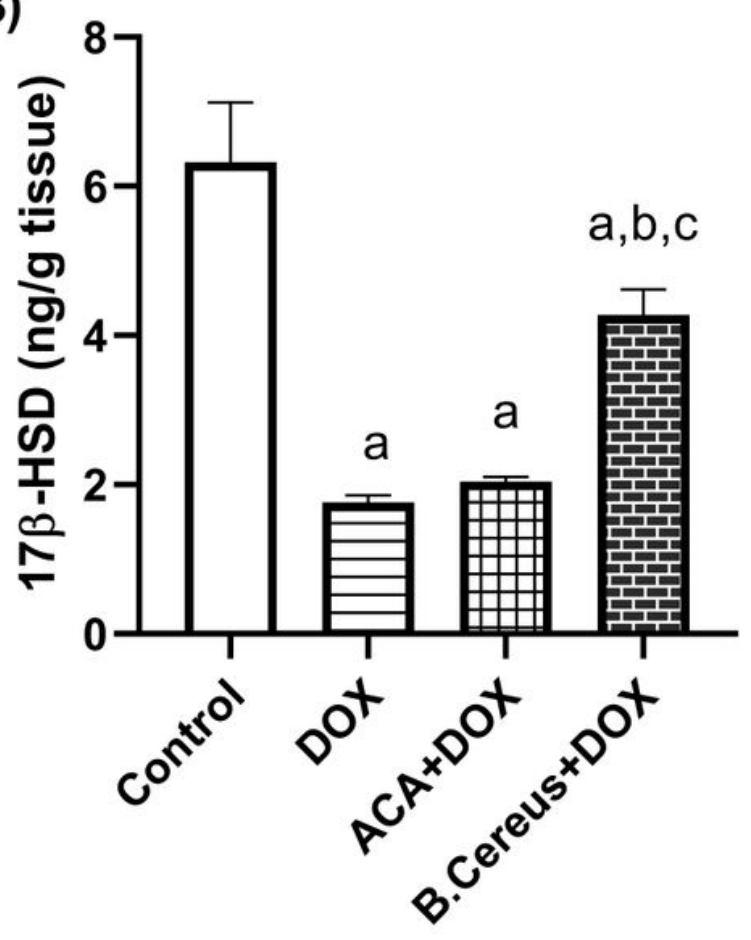

Figure 1

Effect of ACA and B. Cereus protease on serum testosterone level (A), and on testicular 17 $\beta-H S D(B)$ in DOX-induced testicular toxicity in rats: Each bar with a vertical line represents the mean \pm S.D $(n=6){ }^{a}$ Compared with the control group, ${ }^{b}$ compared with the DOX group, and ${ }^{c}$ compared with the ACA+DOX group. All values are statistically significant

at $p<0.05$. Abbreviations: ACA: acacetin; B. Cereus: Bacillus Cereus protease; 17 $\beta-H S D: 17$ betahydroxysteroid dehydrogenases; DOX: doxorubicin. 
(A)

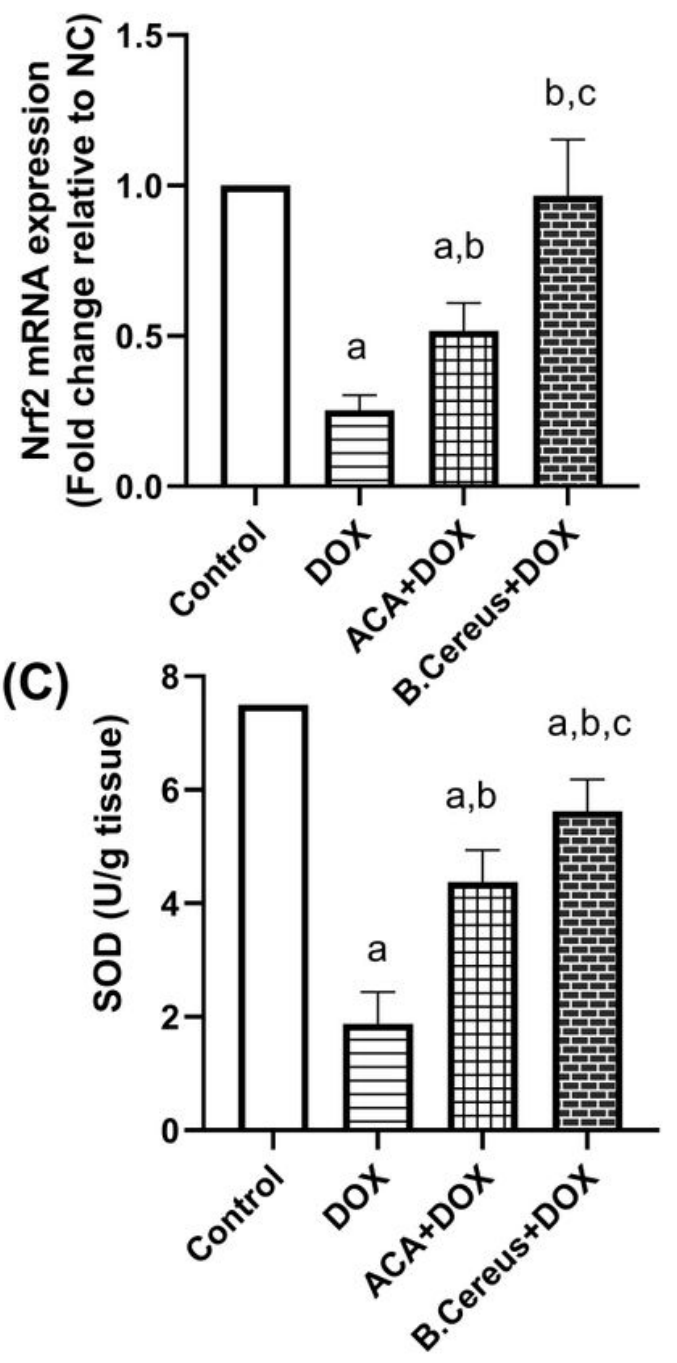

(B)

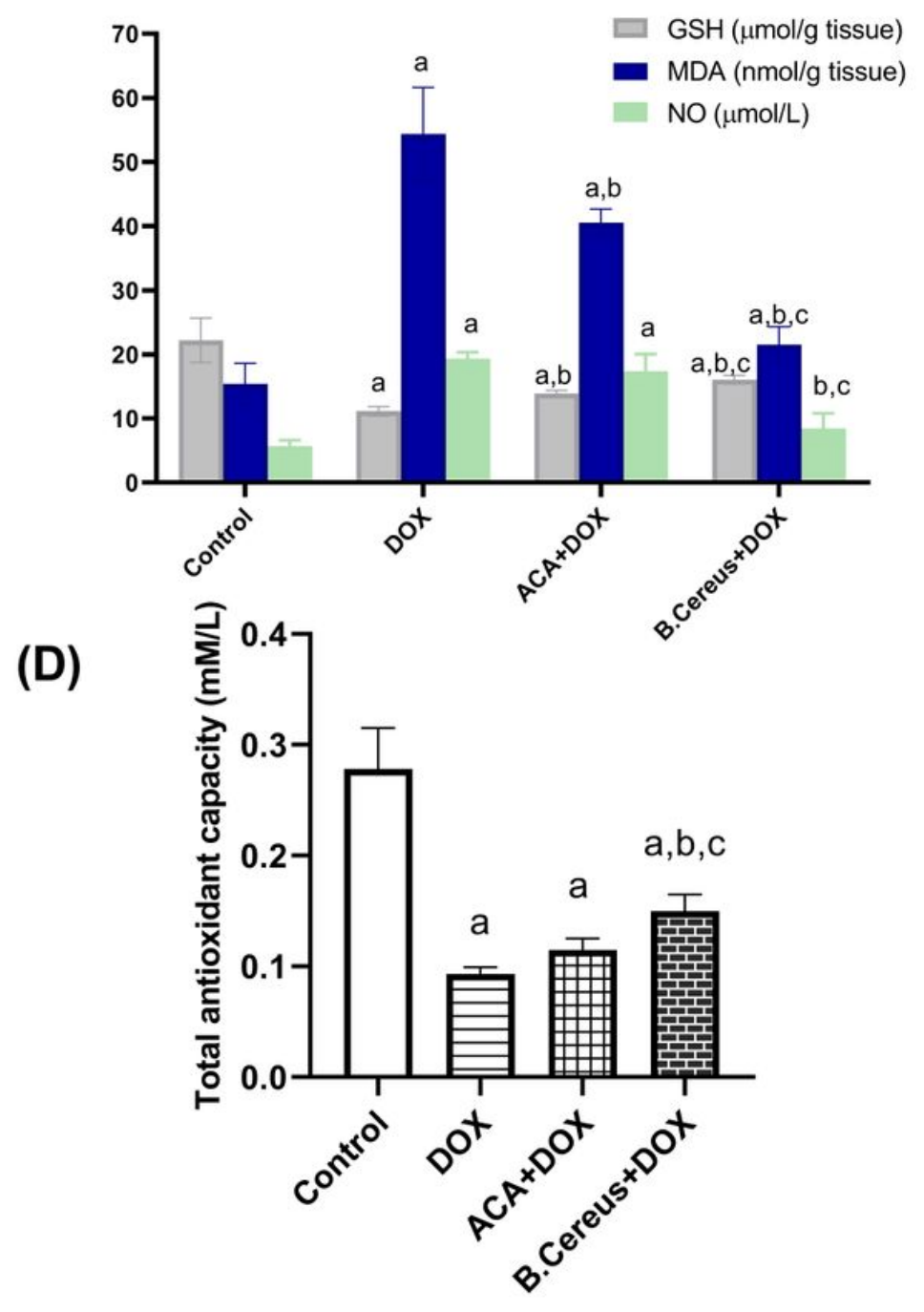

Figure 2

Effect of ACA and B. Cereus protease on Nrf2 gene expression (A), GSH; MDA; and NO levels (B), SOD activity (C), and TAC (D) in DOX-induced testicular toxicity in rats: Each bar with a vertical line represents the mean \pm S.D $(n=6) .{ }^{a}$ Compared with the control group, ${ }^{b}$ compared with the DOX group, and ${ }^{c}$ compared with the ACA+DOX group. All values are statistically significant at $p<0.05$. Abbreviations: ACA: acacetin; B. Cereus: Bacillus Cereus protease; DOX: doxorubicin; GSH: reduced glutathione; MDA: malondialdehyde; Nrf2: The nuclear factor erythroid 2-related factor 2; NO: nitric oxide; SOD: superoxide dismutase; TAC: total antioxidant capacity. 
(A)

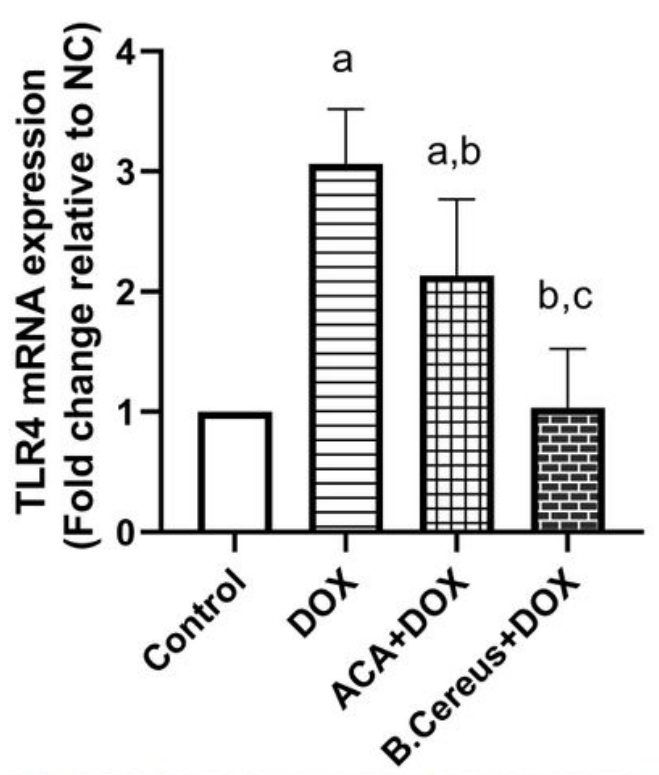

(C)

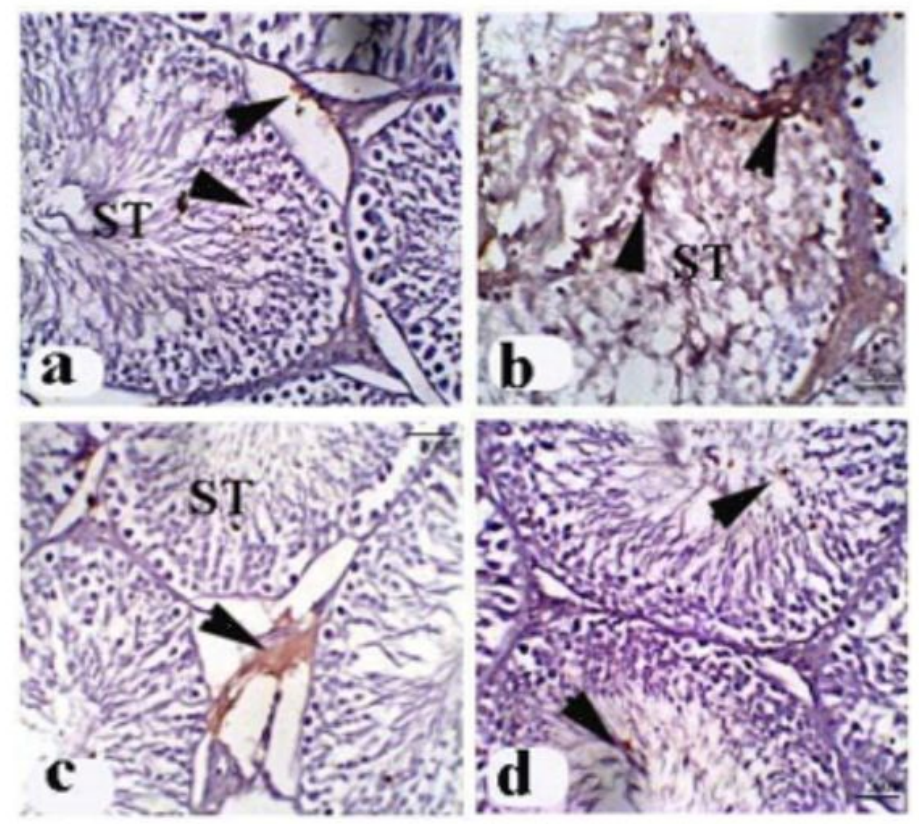

(B)

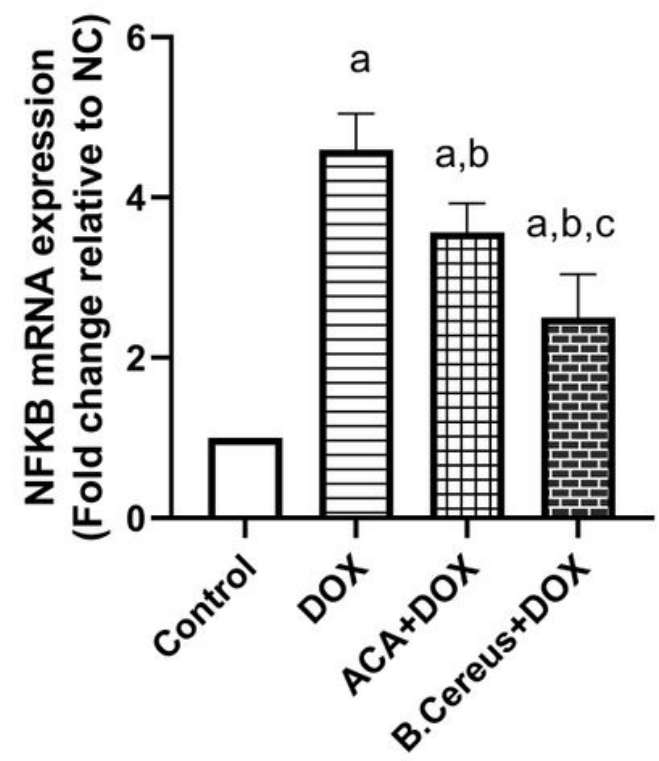

(D)

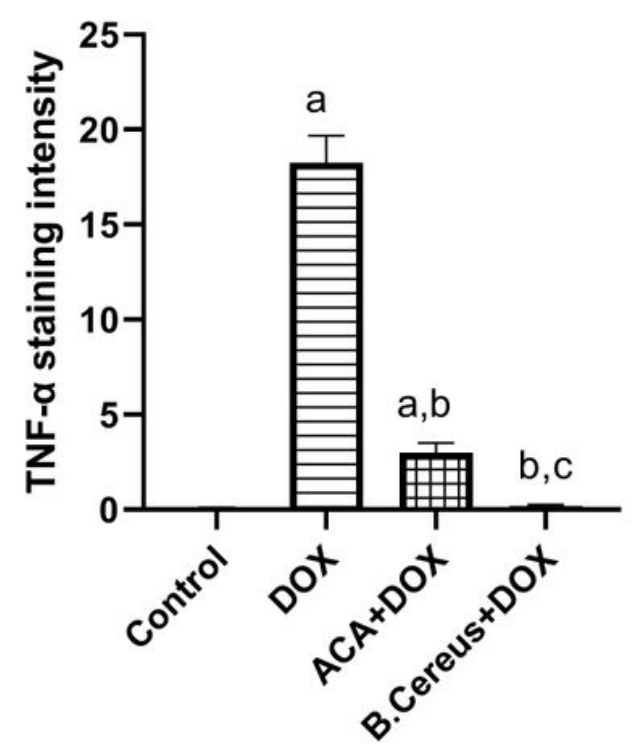

Figure 3

Effect of ACA and B. Cereus protease on inflammatory biomarkers; TLR4 (A), NF-kB (B) gene expressions, and TNF- $\mathrm{X}(\mathrm{C})$ protein expression in DOX-induced testicular toxicity in rats: Each bar with a vertical line represents the mean \pm S.D $(n=6)$. Control group (a); DOX treated group (b); DOX +ACA treated group (c); and DOX +B. Cereus protease treated group (d). X 200 (Scale bar $=50 \mu \mathrm{m}) .{ }^{a}$ Compared with the control group, ${ }^{b}$ compared with the DOX group, and ${ }^{c}$ compared with the ACA+DOX group. All values are statistically significant at $p<0.05$. Abbreviations: ACA: acacetin; B. Cereus: Bacillus Cereus protease; DOX: doxorubicin; NF-kB: nuclear factor kappa-light-chain-enhancer of activated B cells; TLR4: Toll Like Receptor 4; TNF-囚: Tumor necrosis factor alpha. 
(A)

(B)

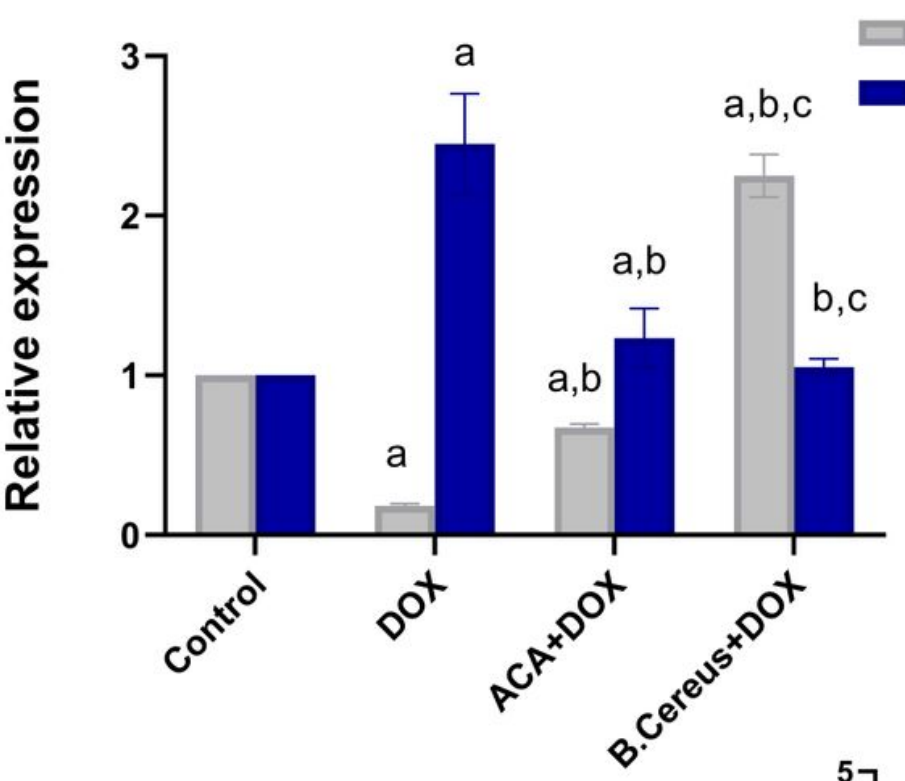

$\operatorname{miR}-34 \mathrm{c}$

miR-155
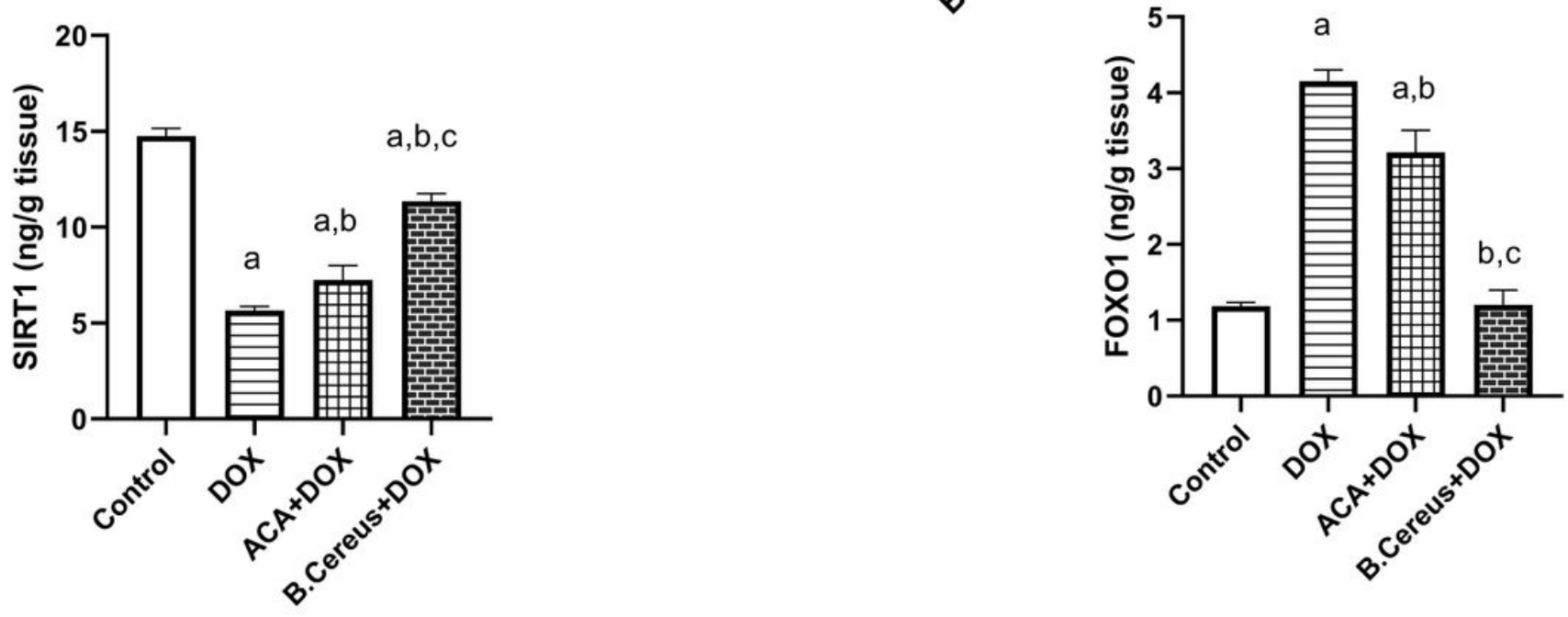

(C)

Figure 4

Effect of ACA and B. Cereus protease on testicular miR-34c and miR-155 gene expressions (A), and testicular SIRT1 (B), and FOX01(C) protein expressions in DOX-induced testicular toxicity in rats: Each bar with a vertical line represents the mean \pm S.D $(n=6)$. a Compared with the control group, b compared with the DOX group, and c compared with the ACA+DOX group. All values are statistically significant at $p<$ 0.05. Abbreviations: ACA: acacetin; B. Cereus: Bacillus Cereus protease; DOX: doxorubicin; FOX01: Forkhead box protein 01 ; miR: microRNA; SIRT1: sirtuin-1. 
(A)

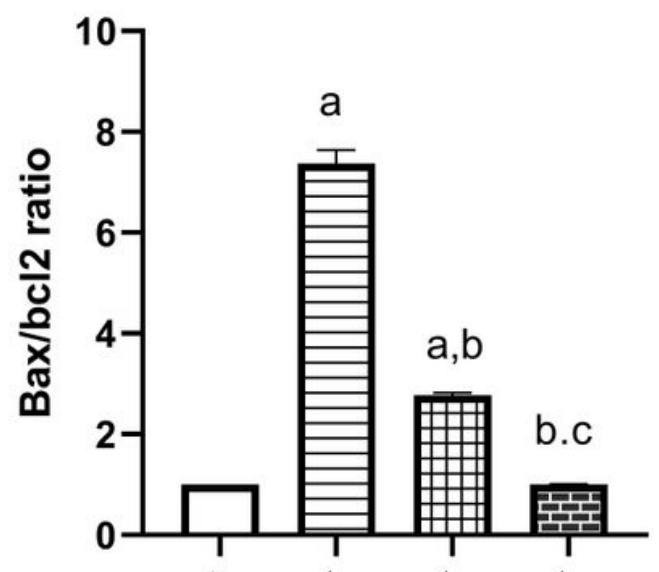

(B)
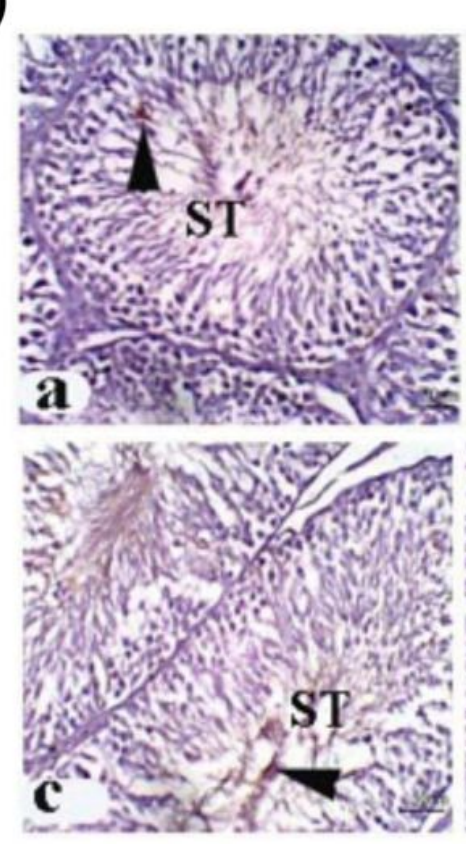
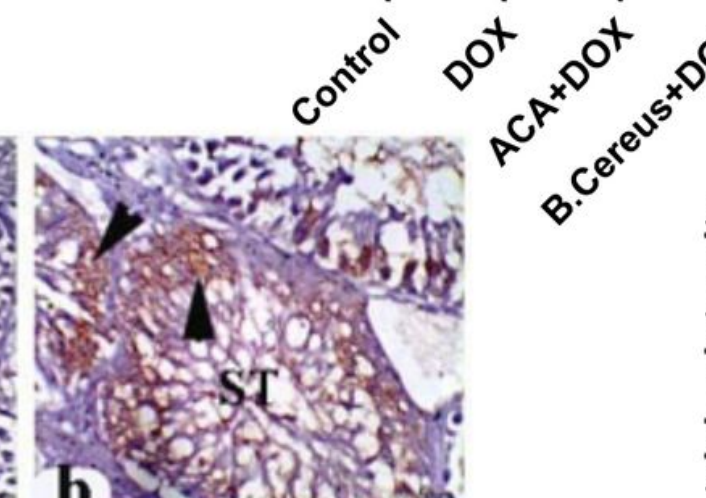

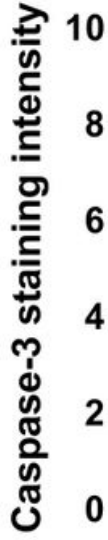

(C)
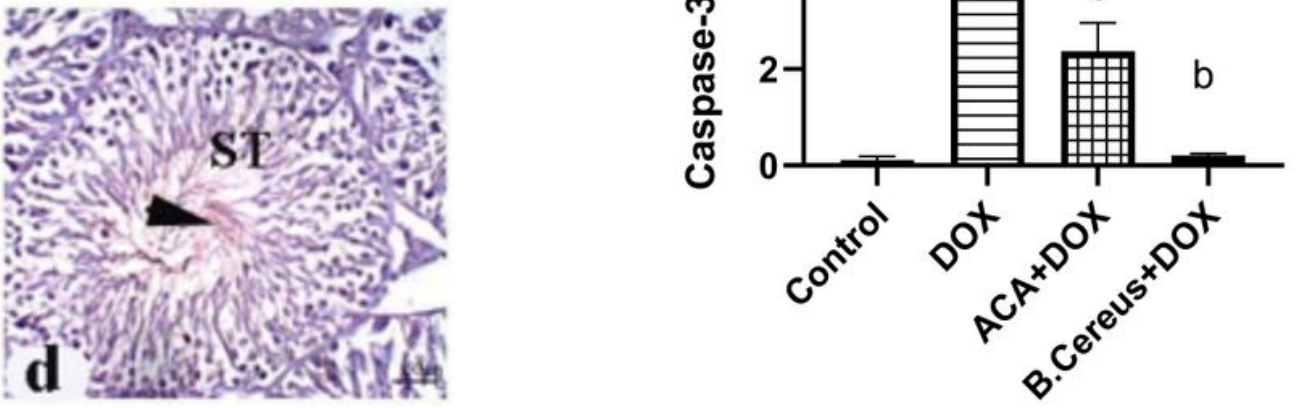

Figure 5

Effect of ACA and B. Cereus protease on Bax/bcl2 ratio (A), Caspase-3 protein level (B), and Caspase-3 staining intensity (C) in DOX-induced testicular toxicity in rats: Each bar with a vertical line represents the mean \pm S.D ( $n=6)$. Control group (a); DOX treated group (b); DOX +ACA treated group (c); and DOX +B. Cereus protease treated group (d). X 200 (Scale bar $=50 \mu \mathrm{m}$ ). Arrow: Brown color is positive reaction of tested marker. ${ }^{a}$ Compared with the control group, ${ }^{b}$ compared with the DOX group, and ${ }^{c}$ compared with the ACA+DOX group. All values are statistically significant at $p<0.05$. Abbreviations: ACA: acacetin; $B$. Cereus: Bacillus Cereus protease; Bax; Bcl-2-associated X protein: Bcl2; B-cell lymphoma 2: DOX: doxorubicin; ST: seminiferous tubules. 

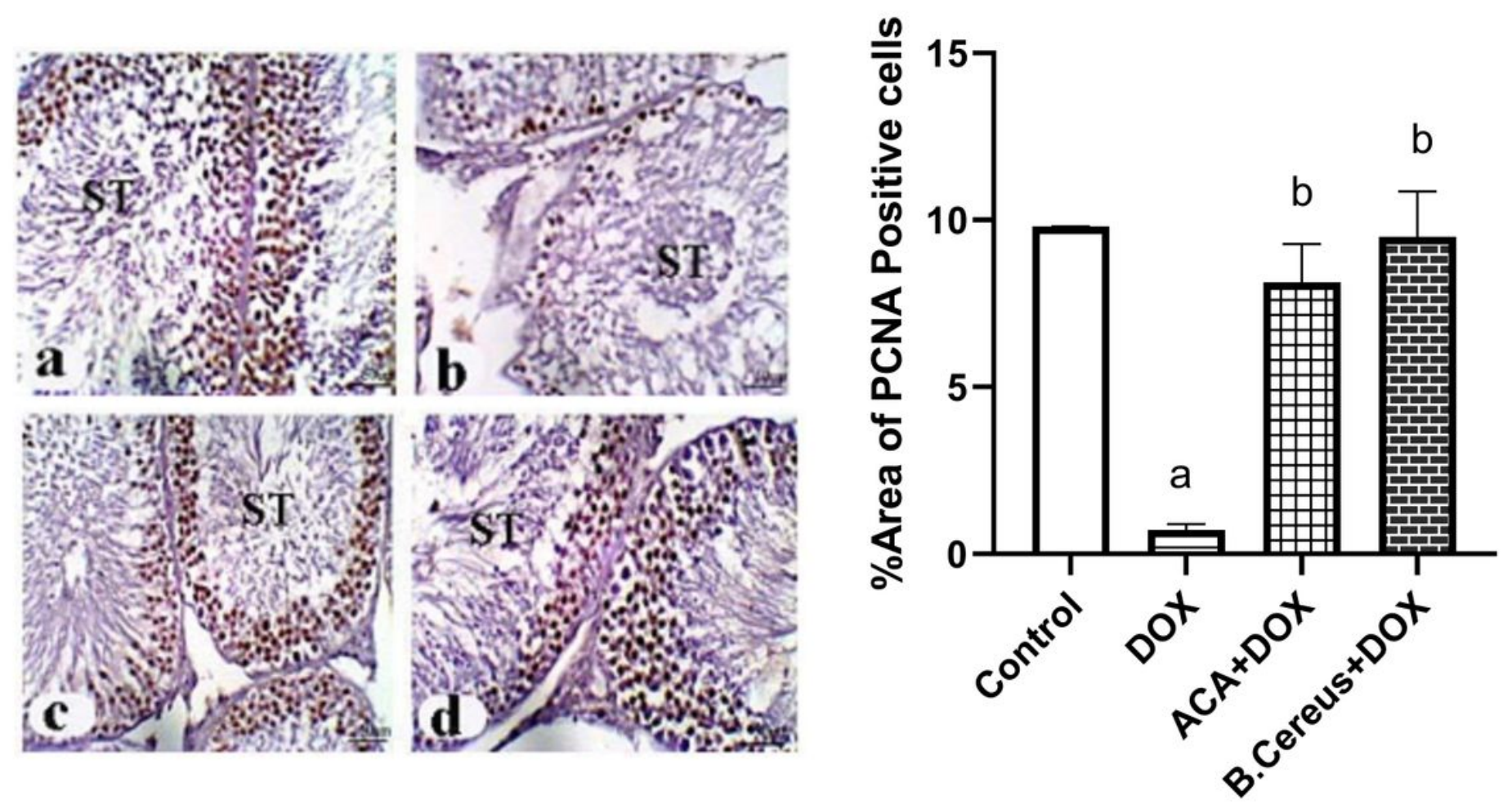

Figure 6

Immunohistochemical expression of PCNA in testis (A) and \% Area of PCNA positive cells (B) in DOXinduced testicular toxicity in rats: Control group (a); DOX treated group (b); DOX +ACA treated group (c); and DOX +B. Cereus protease treated group (d). X 200 (Scale bar $=50 \mu \mathrm{m})$. Each bar with a vertical line represents the mean \pm S.D $(n=6)$. ${ }^{a}$ Compared with the control group, and ${ }^{b}$ compared with the DOX group. All values are statistically significant at $p<0.05$. Abbreviations: ACA: acacetin; B. Cereus: Bacillus Cereus protease; DOX: doxorubicin; PCNA: Proliferating cell nuclear antigen; ST: seminiferous tubules. 

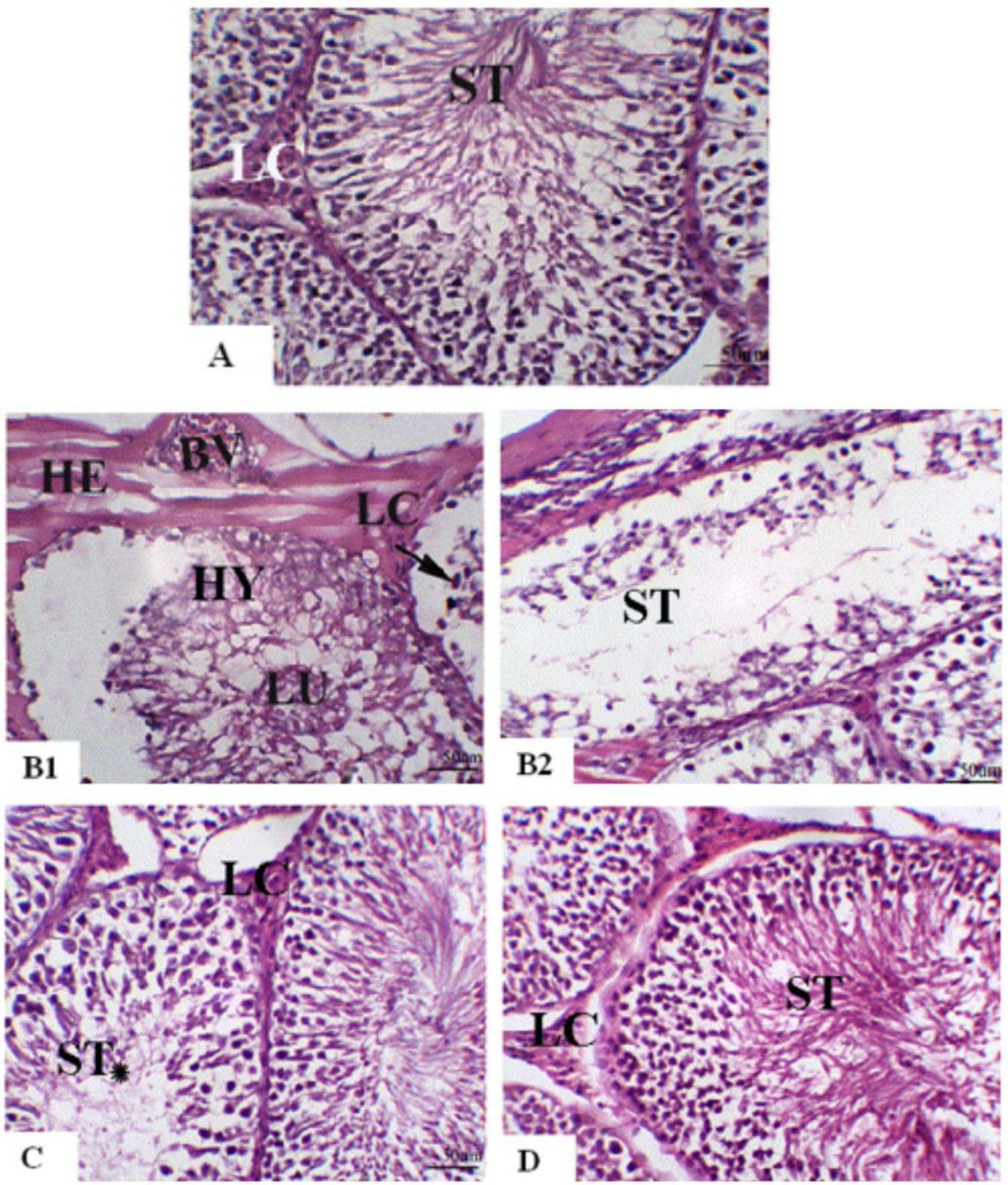

Figure 7

A photomicrograph of testis staining with H \& EX 200, (Scale bar $=50 \mu \mathrm{m})$. Control group (A), DOX treated group (B1\&B2), ACA+DOX treated group (C), and DOX+B. Cereus protease treated group (D). 
Seminiferous tubules (ST); Seminiferous tubules with reduction in spermatogenic layers and completely absence of sperm (ST*); Leydig cells (LC); Exfoliated spermatogenic cells in lumen (LU); Hyaline degenerative changes (HY); Pyknotic nuclei in the basal cell layers (arrow); Hyalinizied congested blood vessels (BV); Hemorrhage (HE).

\section{Supplementary Files}

This is a list of supplementary files associated with this preprint. Click to download.

- Graphicalabstract.tif

- PRISM.pzfx 